Edited by: P.J.B. Slater, J.S. Rosenblatt, C.T. Snowdon, and

M. Milinski. Academic Press, San Diego, CA (1994). Pages 233-270

\title{
Communication Behavior and Sensory Mechanisms in Weakly Electric Fishes
}

\author{
BERND KRAMER \\ ZOOLOGISCHES INSTITUT DER UNIVERSITÄT \\ D-93040 REGENSBURG, GERMANY
}

\section{INTRODUCTION}

Animals are the most complex organisms we know. Most of them show high mobility, sensitivity for the most diverse stimuli, and the ability to process information and learn. Animals are also capable of using resources that are unpredictable or difficult to find or obtain; they can camouflage or disguise themselves; and they can attack or flee.

Such a mode of life disperses the individuals of a population. Sophisticated orientation and communication mechanisms have evolved in many species, enabling individuals to find resources or mates even at exceedingly low densities. It is only in recent years that the power of these orientation and communication mechanisms has begun to be unraveled. Among the most famous examples are the dance language and orientation of bees (von Frisch, 1967); the homing of pigeons over hundreds of kilometers in unfamiliar territory (Keeton, 1979); the often intercontinental migrations of birds from their summer to their winter quarters, and vice versa (Alerstam, 1990); the marine migrations of salmon for several years, followed by their homing to the small streams they were born in by olfactory cues (Hasler and Scholz, 1983); the barn owl's precise localization and flash capture of a rustling mouse in total darkness (Payne, 1962; Konishi, 1993); and the ability of bats to detect and catch flying nocturnal insects by echolocation (Griffin, 1958; reviews by Neuweiler, 1984, 1993; Suga, 1990).

\section{Weakly Electric Fishes}

Less well known are electric fishes, although strongly electric fish (the electric eel, the electric ray, and the electric catfish) played an important 
role in the advent of both the physical study of electricity and the science of neurobiology in the eighteenth and nineteenth centuries (e.g., Wu, 1984). Some of the weakly electric fishes that are considered in this chapter were known by a few eighteenth-century biologists like Carl von Linné; however, it was only in 1951 that $\mathbf{H}$. W. Lissmann of the University of Cambridge discovered these fishes' regular, albeit weak, electric organ discharges (EODs), aided by electronic measuring devices.

Teleost weakly electric fishes comprise the African elephant fishes (Mormyriformes; approximately 200 species) and the South American knifefishes (Gymnotiformes; perhaps 70 species), which are only distantly related. [A recent addition to this list are three "squeakers," members of the exclusively African catfish family Mochokidae, whose behavior is so little known that they are not dealt with in this review (Hagedorn et al., 1990).]

Weakly electric fishes are both electrogenic and electroreceptive. Their electric system consists of a motor part, the usually myogenic electric organ, which is controlled by a pacemaker nucleus in the hindbrain; and a sensory part, the cutaneous electroreceptors, the afferences of which are connected to huge, specialized brain areas [for the motor part, see reviews by Bennett (1971a); for the sensory part: Bennett (1971b), Szabo (1974), and Szabo and Fessard (1974); the more recent developments are traced by several reviews in the volume edited by Bullock and Heiligenberg (1986) and more briefly in Kramer (1990b)].

The electric system of both groups of nocturnal fishes is adapted to two functions: active, EOD-dependent electrolocation (Lissmann and Machin, 1958; review by Bastian, 1986) and communication (reviews by Kramer, 1990a,b). Although their electric systems are superficially similar (Finger et al., 1986), great differences between African (Mormyriformes) and South American weakly electric fishes (Gymnotiformes) are found on a behavioral level. Even within these two groups the diversity is great; therefore, no single species can serve as a "model" electric fish. For a consideration of evolutionary questions, see Finger et al. (1986) and various chapters in Bullock and Heiligenberg (1986), or Kramer (1990b), and the papers cited therein.

\section{Pulse And Wave Fishes}

Weakly electric fishes discharge their electric organs in a pulse- or in a wavelike fashion ("buzzers" or "hummers," named after the sound of amplified EODs when fed into a loudspeaker; Fig. 1). Whether a species is a buzzer or a hummer does not appear to be correlated with ecology 

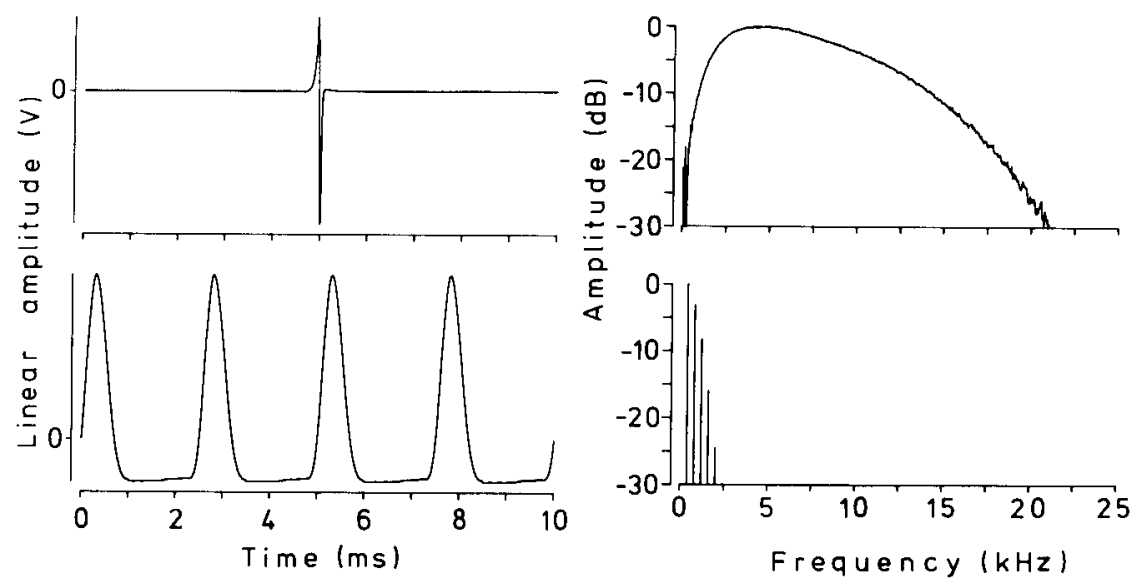

FIG. 1. Pulse (top) and wave (bottom) discharges of two species of weakly electric fishes. A pulse discharge is of short duration (left) and has a broad amplitude spectrum (right); made audible it resembles a click. A wave discharge consists of pulses repeated at an extremely stable frequency; its amplitude spectrum therefore consists of spectral lines, representing the fundamental frequency and its overtones (harmonics). Fed into a loudspeaker, a wave discharge generates a humming sound. Top: Gnathonemus petersii (Mormyridae); bottom: Eigenmannia lineata (Sternopygidae, Gymnotiformes.) From Kramer (1990b).

nor with an adaptation to a special mode of life, but is strongly linked to phylogeny. There are representatives of each discharge type on both of the continents in which they are found, Africa and South America. They are therefore remarkable examples of convergent evolution.

Discharging the electric organ in a pulse- or in a wavelike fashion has consequences for both the forms the signaling can take and the processing of electrosensory information. In most species, an EOD pulse is of short duration and constant waveform, often shorter than a nerve action potential, and of relatively low repetition rate. Therefore, several pulse fishes may all discharge simultaneously, with relatively little risk of temporal coincidences of their discharges (time sharing). On the contrary, a wave EOD is "on" all the time, and the EOD of an individual will be superimposed on that of another if sufficiently close, so that neither can receive its own EOD in "pure" form; therefore, the individuals of a community of wave fishes rarely discharge at the same frequency (frequency sharing).

We may add that in pulse fishes (especially in mormyrids) the discharge rate tends to be low and unstable, whereas the wave fishes' discharge frequency may be very high (depending on the species, up to $1800 \mathrm{~Hz}$ ), 
but certainly very stable, probably more so than any other biological signal source. While in pulse fishes the EOD amplitude is usually high (in a few species so high that the discharge is felt by the human hand touching a moist fish, sometimes even causing discomfort), the EOD amplitude of wave fishes is generally much weaker.

The amplitude spectrum of a single pulse EOD shows a continuous distribution of frequencies, rising from dc to a broad peak region before leveling off at still higher frequencies (Fig. 1). An amplitude spectrum of a wave discharge, on the contrary, shows energy only at specific points, the fundamental frequency and its harmonics or overtones (which are integer multiples of the fundamental), with no energy in between (nor at dc). Therefore, a pulse EOD's artificial acoustic representation is broadband, sounding click-like to the human ear, whereas that of a wave EOD is "harmonic" like the sound of a flute or similar musical instrument, with a characteristic timbre depending on the number and relative intensity of overtones.

Both pulse and wave fishes have been shown to be exceedingly sensitive to the fine detail of their discharge, which usually varies among the individuals of a population. Some forms and mechanisms of communication will be discussed for both the African and the South American weakly electric fishes.

\section{The Interdischarge Interval Code in the Mormyridae}

All elephant fishes (Mormyridae) tested have been found to discharge their electric organs in a pulselike fashion; their monospecific relative, Gymnarchus niloticus, is the only known African wave fish. So little is known about its communication behavior that it is not dealt with here (but see the review by Kramer, 1990b, and the papers cited therein).

A pulse fish's EOD activity has two aspects: the waveform of its EOD and the sequence of interdischarge intervals. Although the EOD waveform is fixed for a certain individual (there are exceptions, see Section VI), the pattern of interdischarge intervals is highly variable from moment to moment, and thus can encode the slightest change of state of excitement, and also specific "messages" addressed to conspecifics dיring social interactions (Fig. 2). Therefore, mormyrids have an interdischarge time interval (IDI) code of communication.

It is one thing to encode a message and another to decode it. On a very technical level we may ask, for example: Are mormyrids able to "measure" the variation of inter-EOD time intervals, as generated by conspecifics in various ethological contexts? The only species tested, 

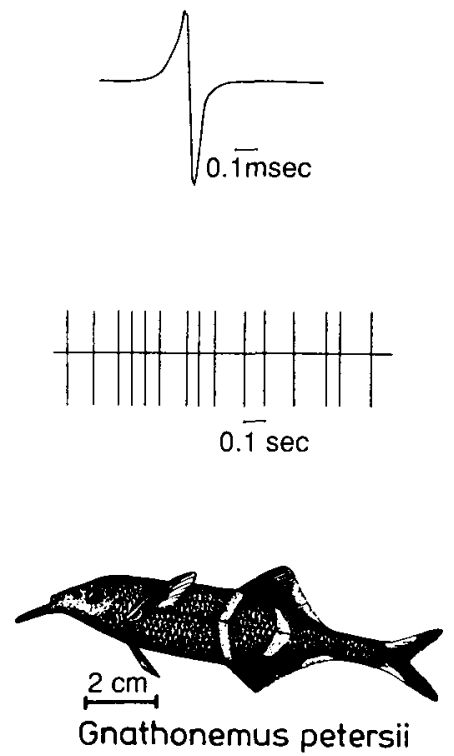

Fig. 2. The electric organ discharge of a mormyrid has a species-characteristic waveform (top) that is extremely stable for an individual. The sequence of pulse intervals is, however, variable and reflects the state of excitement of a fish in a species-characteristic manner (Gnathonemus petersii). Note difference in time bars by a factor of 1000 . From Kramer (1985b).

Pollimyrus isidori, is an "expert" in the precise measurement of interpulse time intervals: trained, food-rewarded individuals discriminate a change of as little as $2 \%$ in a train of pulses spaced by $50 \mathrm{~ms}$, and $3 \%$ at $100 \mathrm{~ms}$ (Kramer and Heinrich, 1990). This discrimination performance was achieved with either the rewarded or the unrewarded pulse train presented one at a time (well separated from the next presentation by random intervals varying between $30 \mathrm{~s}$ and $3 \mathrm{~min}$ ); that is, without direct comparison of stimuli, in a similar way to the capacity of certain humans who are endowed with "absolute pitch."

An IDI code of communication was already suggested by one of the first experimental studies using pairs of resting mormyrids (Moller and Bauer, 1973; see also Moller et al., 1989). Since then, the IDI code has been demonstrated for several behavioral functions, including aggressive signaling (Bauer, 1972; Kramer, 1974, 1979; Bell et al., 1974; Kramer and Bauer, 1976; Bratton and Kramer, 1989); "threat" signals from fish attacked by an aggressive conspecific, shown also during escape behavior (Kramer, 1976); group cohesion (Moller, 1976; Serrier and Moller, 1981; Moller et al., 1982; Moller and Serrier, 1986; Graff, 1986); the specific 
EOD latency response, a form of entrained electrical signaling (Bauer and Kramer, 1974; Kramer, 1974; Russell et al., 1974); species recognition (Kramer and Lücker, 1990); and electrical signaling during courtship and spawning behavior (Bratton and Kramer, 1989; Crawford, 1991).

Because of its presence in all the species used in these studies, and almost all other mormyrids tested, it is likely that an IDI code of communication, in a species-characteristic form, is present in all members of the Mormyridae (i.e., it is a symplesiomorphy or shared trait in all members of a taxon in the sense of Hennig, 1966). As an example, the electrical signaling in the courtship and spawning of the small mormyrid $P$. isidori will be described. It became possible to study the reproductive behavior of mormyrids in captivity after Birkholz's (1969) and Kirschbaum's (1975, 1987) breeding successes in aquaria. Electrical communication in mormyrids has also been reviewed by Moller (1980a), Hopkins (1986), and Kramer (1990b).

\section{Electrical Signaling in the Courtship and Spawning of a MORMYRID FISH}

During its diurnal resting behavior at the bottom of a shallow West African river or stream, in the shelter of rocky crevices or tree roots, the mean discharge rate of a $P$. isidori is low ( $<10$ pulses per second, or pps) but varies from moment to moment. Every 2-3 s there is a brief, sharp EOD rate acceleration. Attacks on conspecifics, which are more common during the night, are also accompanied by sharp EOD rate accelerations but are followed by a high discharge rate display at or beyond $100 \mathrm{pps}$. These electrical displays are an obligatory component of the motor pattern "attack" and have signal value (Kramer, 1978, 1979; Bratton and Kramer, 1989).

Totally different is the signaling of a female with a ripe ovary (mormyrids have only one gonad on their left side). After dark she signals her readiness to spawn by ticking away regularly like a clock, at a very low discharge rate of only 6-8 pps. In the life of a $P$. isidori, a low rate of EODs generated at constant intervals occurs only during the time of reproduction, and only at night when courtship or spawning will occur.

Although not yet observed in the wild, but very likely from aquarium observations, the female appears to wander about to choose among the territorial males that try to attract her attention with their long-range advertisement calls. These songs, which only the males produce, take on the form of deep grunts, growls, and moans (Crawford et al., 1986) and are especially intense and of long duration on contact with a female emit- 


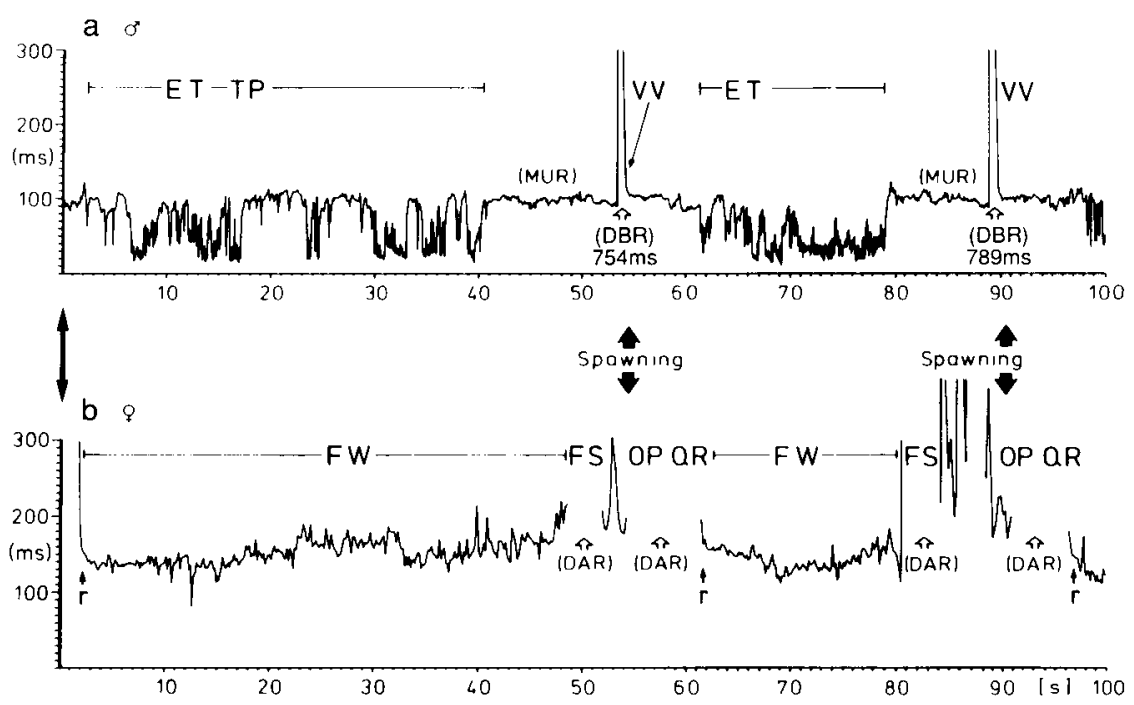

FIG. 3. Electric communication in a mating pair of Pollimyrus isidori during their nocturnal spawning (a, male; b, female). The ordinates are the interdischarge time intervals (ms); neighboring points are connected by lines to show a trend. The abscissas are time (s). The record begins with the female just returning (r) to her waiting site ( $F W$, female wait phase). During this time, the male performs housekeeping activities (ET, egg transport: TP, territory patrolling) while displaying a "high sporadic rate sequence" of EOD activity, including many bursts of high discharge rate. As soon as the female arrives at the spawning site (FS, female spawning site wait for male) the male switches to the "medium uniform rate" (MUR) of much lower rate, as constantly displayed by the female as her "readiness-to-spawn" signal. During close contact, especially vent-to-vent coupling (VV) and oviposition (OP), short discharge breaks (DBR) or longer discharge arrests (DAR) are observed. After the female quiver $(\mathrm{QR})$, she returns to her home region, followed by the male's switching back to his MUR discharge pattern. From Bratton and Kramer (1989).

ting her electrical readiness-to-spawn display (Bratton and Kramer, 1989; Crawford, 1991).

As in many other fishes, at this point spawning is still no more than a possibility. Before spawning occurs, there will be much more singing by the male, which he does almost continuously, while also attacking the female severely, as if to drive her away. This behavior may seem odd at first but is probably necessary because of the females' eagerness to eat any eggs or larvae that a male may be guarding. (A male normally guards the fry from several spawnings and is extremely aggressive toward any conspecific approaching its nest, including females ready to spawn). Perhaps the long courtship phase (of about $3 \mathrm{hr}$ on a spawning night), in addition to allowing time for the synchronization of the reproductive physi- 
ology of the mates, also serves to test the "intentions" of a female-will she be an egg producer or an egg eater?

Spawning becomes much more likely when the engagement phase begins (about $1 \mathrm{hr}$ after dark). In spite of still being severely attacked, the female rapidly descends in the water column and stops swimming on the bottom close to the nest. Instead of dealing the female a deadly blow, as one might expect from his previous aggressive behavior, the male immediately switches from the rather high and variable discharge rate he usually displays when guarding the eggs (ET-TP in Fig. 3) to the same EOD pattern displayed by a female who is ready to spawn (see Fig. 3, bottom): a very low EOD rate at almost constant inter-EOD intervals (6-8 pps). He tries to back up from behind and to position himself alongside the female, who quickly turns through $180^{\circ}$, and this leads to rapid head-to-tail circling of both fish for a few seconds (Fig. 4), ended by the female's hasty escape to her hiding place high up in the water column where she is relatively safe.

The male who had stopped singing immediately switches back to his high and variable EOD rate (Fig. 3, at times designated by " $r$ " in the female record) and directs dangerous "courtship attacks" at the female while intensely singing. The female repeats her brief visits to the male's territory once or twice a minute despite the male's aggression, whose singing rapidly wanes to almost nothing. The female's shyness also wanes and she allows the male to position himself along her side. The male pitches head downward and rolls on his side $90^{\circ}$ while engaging the female's anal fin with his own. While so coupled tightly vent-to-vent, the female is pushed upward, and both fish perform a complete, slow somersault rotation. Only then do the fish disengage and the female rapidly swims away.

After repeating this rather elaborate exercise for about $2 \mathrm{hr}$, usually at a rate of once or twice per minute, spawning may begin (Fig. 4G). The spawning behavior resembles the courtship behavior in every aspect, including that of electrical communication, except that the "somersault rotation" is skipped. On the female's arrival at the spawning site the male lines up in parallel and quickly rotates to one side, stimulating the female's anal fin region with his own in a quivering action. After she releases a few eggs the female disappears while the male fertilizes the eggs (his sperm is immobile because the spermatozoa lack flagella).

The male transports the eggs in his mouth to the nest, where he sticks them into plant material (Java moss in the laboratory setting). As she did during the preceding courtship period, the female continues to visit the spawning site once or twice per minute until all eggs are shed (usually up to 200 in one night). This can take $4 \mathrm{hr}$. Only then does the female stop visiting the spawning site, whereupon she also changes her EOD activity: 


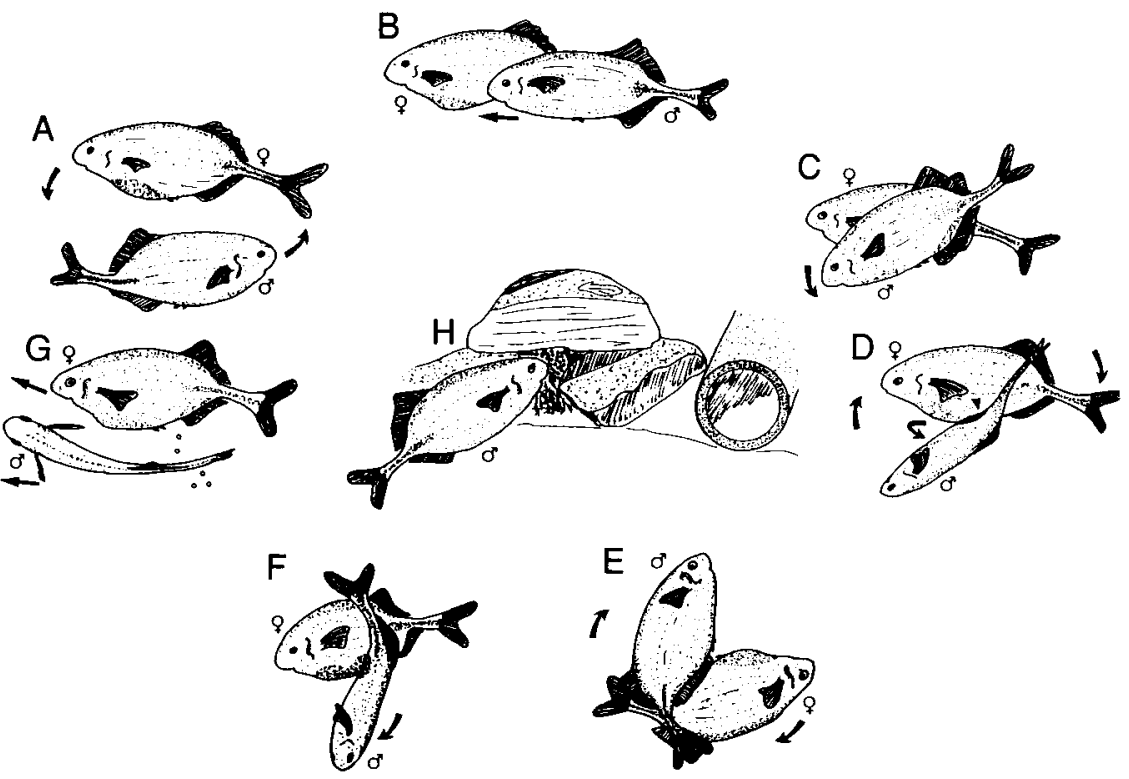

FIG. 4. The nocturnal courtship and spawning behavior in Pollimyrus isidori, redrawn from infrared video recordings. See text; $\mathrm{H}$, the nest with eggs; A, head-to-tail circling; $\mathrm{B}$, male arriving alongside of the stationary female; C-D, vent-to-vent coupling; E-F, rotation; G, oviposition. From Bratton and Kramer (1989).

she begins to regularly alternate between a high (about $70 \mathrm{pps)}$ and a low EOD rate (about 5 pps), at two changes per second. The male, who did not sing for most of the courtship and the whole spawning period, starts to sing again intensely. He constantly patrols his territory, searching for any stray eggs that he picks up and puts into his nest.

Why does the male sing at all? He could probably just as well signal his state of being a breeding male with a territory and a nest by using a purely electrical display. There may be two reasons why sound is involved: (1) It appears that the useful range of the male's song is greater than that of his weak electrical discharge so that the probability of encountering a suitable mate is enhanced by the use of sound. (2) EODs may not be so well suited to inform females about the "quality" of a mate, compared to a courtship song that occurs only in males and probably is more costly (in terms of both energy expenditure and predation risk). The frequency of the song (especially the moan part), its intensity, and its duration may give females a better indication about a male's age, reproductive state, health, and ability to successfully defend and care for the brood than any electric organ discharge display, since EODs are also part of ordinary life 
and therefore subject to many other selection pressures (e.g., arising from their electrolocation and social cohesion functions).

It seems to be advantageous for the male to stop singing at the earliest moment (which he actually does after establishing a more than passing contact with a female ready to spawn), because of the acoustically competent predators that abound in tropical fresh waters. After all, nocturnal electrocommunication in mormyrids probably has evolved in response to pressure from visual predators (like the tigerfish, Hydrocynus forskalii, Characiformes); there is no point in exchanging these for acoustic ones (e.g., Clarias catfishes).

\section{Individual Discrimination In a MORMyrid Fish}

Does a mating pair of elephant fishes know each other individually? In the case of $P$. isidori we cannot help thinking that they must, otherwise the hundreds of short separations occurring during a spawning night (see previous section) would greatly increase the risk of strange females successfully stealing eggs or fry from the nest of an unaware male. [Egg eating may increase a female's individual fitness considerably; see the review by FitzGerald (1992).] A damselfish male recognizes its territorial neighbors individually by their vocalizations (Myrberg and Riggio, 1985), probably an example of the "dear enemy effect" (Fisher, 1954; discussion in McGregor, 1991). It is not yet known whether territorial $P$. isidori males also recognize each other by the small individual variations of the acoustic properties of their songs.

Although it has been said that some mormyrids show individuality by their "personal fingerprint" IDI patterns (Bauer, 1974; D. Malcolm, cited in Moller, 1980b; not particularly supported by Teyssèdre et al., 1987), to date there is little compelling evidence that this actually plays a role in communication, given the volatility of these patterns (see Kramer, $1990 \mathrm{~b}$ ). In the case of $\boldsymbol{P}$. isidori females that are ready to spawn, an individual-specific EOD pattern is even more difficult to imagine because of the simplicity and monotony of the pattern, leaving little room for marks of individuality (see previous section).

By contrast, the EOD waveform shows great intraspecific variability in $P$. isidori (Lücker and Kramer, 1981), and sexually dimorphic EOD waveforms as well as amplitude spectra, assumed to be the basis of mate recognition, were suggested by Westby and Kirschbaum (1982). However, these latter claims had to be substantially reduced (Bratton and Kramer, 1988), mainly because a method of sexing nonbreeding fish employed by Westby and Kirschbaum was found to be unreliable by Bratton and 
Kramer in their population of the same species, and also because of an unnaturally high water conductivity. Mate recognition occurs in part by acoustic rather than electric signals in this species, as well as through cues from the ecological and behavioral context (Crawford et al., 1986; Bratton and Kramer, 1989; Crawford, 1991); see previous section.

Instead of a clear-cut sexual dimorphism like, for example, the antlers of red deer stags or the peacock's tail, what Bratton and Kramer (1988) found in the two sexes of their laboratory population of $P$. isidori (consisting of both breeding and nonbreeding fish kept in water of a natural, low conductivity of $100 \mu \mathrm{S} / \mathrm{cm}$ ) was broad overlapping of the distributions for the EOD waveform parameter, P1/P2 amplitude ratio (Fig. 5A and Table I). [In natural habitats of $P$. isidori in the Comoé and Bandama rivers in the Ivory Coast, water conductivity was $90-95 \mu \mathrm{S} / \mathrm{cm}$ during the beginning of the rainy season of late April and early May of 1990 and 1991 (B. Kramer, personal observation).] The means of the P1/P2 amplitude ratio are statistically significantly different for the two sexes (Bratton and Kramer, 1988), partially supporting and making more specific an initial similar claim by Westby and Kirschbaum (1982).

In males the amplitude of the first head-positive peak is lower than the second, whereas females tend to have a relatively higher P1 phase (in males, the range of the ratio is from 0.04 to 0.94 ; in females, 0.37 to 3.33 ; i.e., the females overlapped two-thirds of the male range). Because of this overlap only a minority of individuals could be reliably sexed by using the EOD waveform; no statistically significant difference emerged in any of several other EOD waveform measures, including duration data and spectral amplitude properties (Bratton and Kramer, 1988).

In a group of six females and eight males that were breeding in the laboratory in water of low conductivity (35 \pm S.E. $6 \mu \mathrm{S} / \mathrm{cm}$ ), the amplitude of the P1 phase of their EOD showed less overlap compared to Bratton and Kramer's fish (Fig. 5B), but still five or six individuals, that is, more than one-third, were in the overlap region (Crawford, 1992). Only when P1 amplitude was plotted against a second parameter, total EOD duration (itself not significantly different between the sexes), did the score combinations for female and male EODs not overlap. However, there is no evidence for the assumption that fish actually perform such a two-parameter analysis, and a two-parameter separation may arise from chance alone considering the small sample size of fish used. Although a larger number of individuals would have been desirable for this hypothesis, this result may indicate that in $P$. isidori that are breeding the EOD waveform could be used as a cue for mate recognition, but for some unknown reason it is not used (as shown in the next paragraph). 


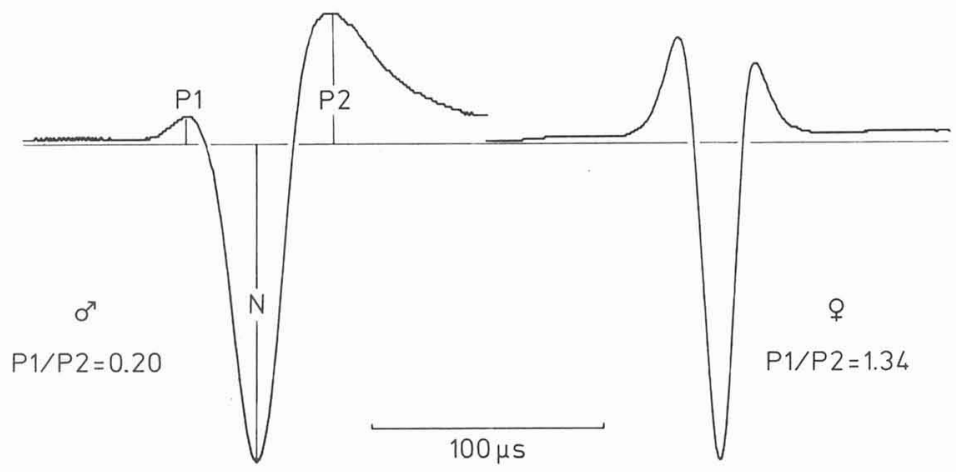

B

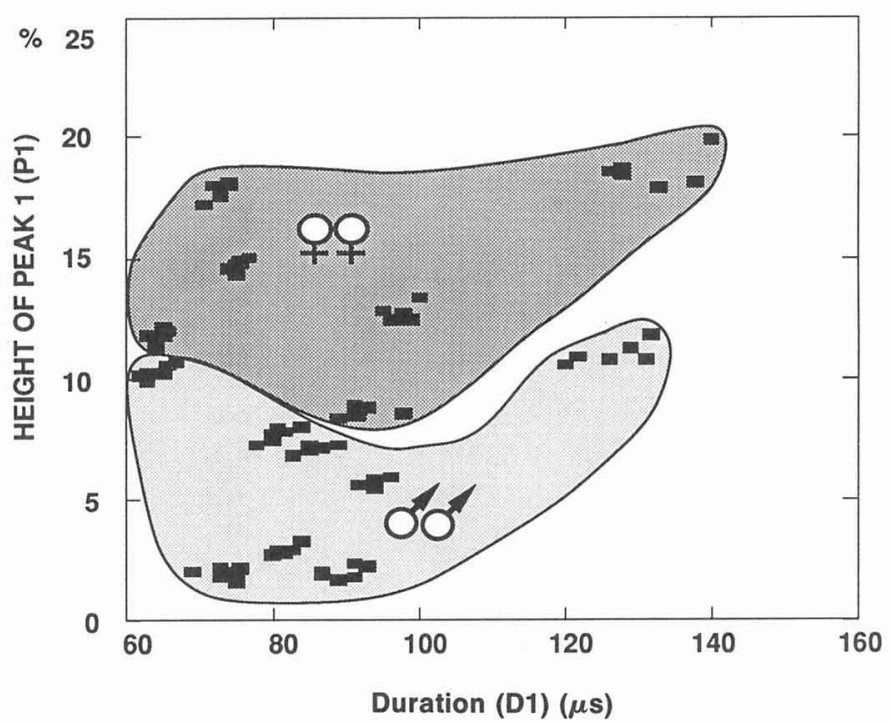

FIG. 5. (A) Oscillograms of the electric organ discharges of two Pollimyrus isidori, showing the great interindividual variability (at a natural $100 \mu \mathrm{S} / \mathrm{cm}$ water conductivity). Individuals were selected to show a difference in EOD waveform for the two sexes: males tend to have a lower P1/P2 amplitude ratio than females, but many individuals of the laboratory population had values lying in the overlap region, and hence could not be reliably sexed on the basis of the EOD waveform. Head-positivity is up; $2 \mathrm{MHz}$ digitization. From Bratton and Kramer (1988). (B) Plot of all 14 individuals breeding in the laboratory $(35 \pm 6 \mu \mathrm{S} / \mathrm{cm}$ ), as represented by their scores on two EOD variables: the amplitude of the P1 phase (as percentage of the total peak-to-peak amplitude of an EOD) and total EOD duration (each individual is represented by six points, i.e., measurements, taken on the same day). Note that the two sexes differ significantly in P1, although 5 individuals are in the overlap region. There is no significant difference for the duration of the EOD; however, in a two-parameter plot such as this one, the area for the males does not overlap with that for the females in these 14 fish. Reproduced with permission from Crawford (1992) and Company of Biologists Ltd. 
TABLE I

EOD WaVeform Variability at $100 \mu \mathrm{S} / \mathrm{cm}$ in Pollimyrus isidori (Given as Ranges or Means \pm Standard Deviation $)^{a}$

\begin{tabular}{|c|c|c|c|}
\hline & $\begin{array}{c}\text { Males } \\
(N=10)\end{array}$ & $\begin{array}{c}\text { Females } \\
(N=14)\end{array}$ & Mann-Whitney $U$ \\
\hline $\mathrm{P} 1 / \mathrm{P} 2$ ratio & $0.04-0.94$ & $0.37-3.33$ & \\
\hline Mean P1/P2 ratio $^{b}$ & $0.49 \pm 0.26$ & $1.17 \pm 0.82$ & 30.5 \\
\hline Mean $100(\mathrm{P} 1-\mathrm{P} 2) / \mathrm{N}^{b}$ & $-19 \pm 13$ & $-4 \pm 13$ & 31.0 \\
\hline $\mathrm{N}$ duration $(\mu \mathrm{s})$ & $23.1-37.8$ & $17.3-31.6$ & \\
\hline Mean $\mathrm{N}$ duration ${ }^{c}$ & $28.6 \pm 5.3$ & $25.8 \pm 3.9$ & 52.0 \\
\hline $\mathrm{P} 1-\mathrm{N}$ separation $(\mu \mathrm{s})$ & $17.8-28.9$ & $15.8-25.8$ & \\
\hline Mean P1-N separation ${ }^{c}$ & $23.0 \pm 3.6$ & $20.5 \pm 2.7$ & 45.0 \\
\hline $\mathrm{P} 1-\mathrm{P} 2$ separation $(\mu \mathrm{s})$ & $33.8-60.9$ & $28.9-52.4$ & \\
\hline Mean P1-P2 separation ${ }^{c}$ & $47.0 \pm 9.5$ & $41.8 \pm 7.4$ & 51.0 \\
\hline Peak amplitude frequency $(\mathrm{kHz})$ & $8.0-20.0$ & $10.5-25.0$ & \\
\hline $\begin{array}{l}\text { Mean peak ampl. frequency } \\
(\mathrm{kHz})^{c}\end{array}$ & $13.4 \pm 4.0$ & $16.4 \pm 4.4$ & 42.5 \\
\hline
\end{tabular}

${ }^{a}$ For definition of P1, P2, and N, see Fig. 5A. N-wave duration was measured as the time between zero-crossings. Peak amplitude frequencies were determined from amplitude spectra (as in Fig. 1, top). Note that there is a statistically significant difference of the mean $P$ ratio between the sexes (second row). All other waveform parameters do not differ significantly between the sexes (Bratton and Kramer, 1988).

${ }^{b}$ Differences significant at $p<0.025$ (Mann-Whitney $U$-test, two-tailed).

${ }^{c}$ Difference not significant $(p>0.10)$.

Because females with male-typical EOD waveform spawned repeatedly without any problem (Bratton and Kramer, 1989), and as also shown by specifically designed experiments that used artificially generated male and female EOD waveforms that were interchanged in combination with different IDI patterns (Fig. 6; Crawford, 1991), the EOD waveform cannot be a salient cue in the mate formation of $P$. isidori.

Why then is there a difference in EOD waveform for the two sexes of $P$. isidori, even if only of a statistical (but significant) nature for the population at large, although-perhaps-nearly dimorphic for breeding individuals? Two possible reasons come to mind: sexual selection (perhaps in its incipient phase; reviews by Wilson, 1975; Maynard Smith, 1991), which could act through hormonal mechanisms, or the different waveforms could be hormonal "by-products." Bratton and Kramer (1988) argue that the latter explanation is the more parsimonious one. Testosterone has been shown to have an anabolic, strengthening effect on the electric organ in several mormyrids and causes the EOD waveform to change when administered to females (Freedman et al., 1989; Bass, 1986; Landsman and Moller, 1988; Landsman et al., 1990). 

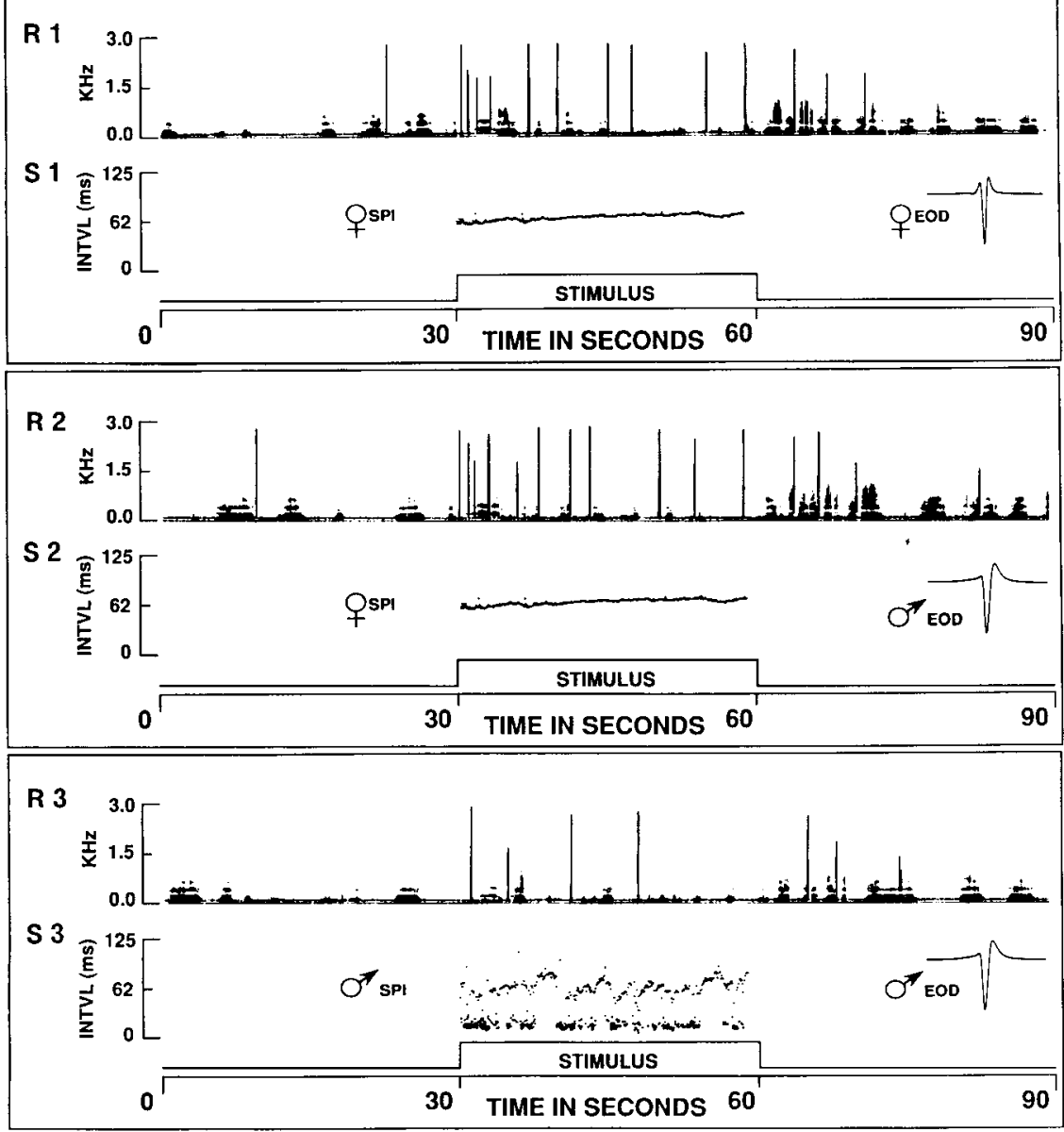

FIG. 6. Acoustic responses (R) of a resident male Pollimyrus isidori to three different combinations of EOD playback via electrodes (S). Acoustic responses are shown as spectrographic charts with frequency $(\mathrm{kHz})$ on the ordinate; grunts are the vertical spikes of broad frequency composition. The sequence of pulse intervals (SPI) is given below in each panel, with each dot being an individual interdischarge interval (ms). Top panel: a female's readiness-to-spawn discharge pattern of low and constant rate evokes a high rate of male grunting, even when combined with a male EOD waveform (middle panel). However, when this male EOD waveform was combined with a discharge pattern recorded from a male that displayed a "high sporadic rate" (Bratton and Kramer, 1989), this evoked less than half the grunt responses in the two other panels. This shows that in order to evoke a high rate of grunting in a nesting, territory-defending male who is ready to court, the interdischarge interval pattern, and not the EOD waveform, of a female is important. Reproduced with permission from Crawford (1991) and S. Karger AG, Basel. 
Even if the difference in EOD waveform between males and females was due "only" to side effects of their hormonal physiology, the presumed result certainly had consequences in evolutionary terms: the enhanced degree of intraspecific variability has, apparently, made possible individual recognition of conspecifics by their EOD waveforms. As shown by Graff and Kramer $(1989,1992)$, trained, food-rewarded $P$. isidori discriminate artificial playbacks of their own species' EODs recorded from different individuals, for example, those shown in Fig. 5A (and also more similar ones; similar results were obtained in Gnathonemus petersii). (For methods of signal generation, see Kramer and Weymann, 1987.)

The ability to recognize its mate individually on a spawning night is of prime importance for a male's reproductive success (see preceding section); a female's EOD waveform might be the only cue available to a male for discriminating among different females. For territorial boundary disputes among neighboring males, however, and from a female's point of view, the males' songs might be an additional (or even better?) source of information allowing the discrimination between individual males.

There are reports of sexual dimorphisms in EOD waveform for several other mormyrid species, sometimes combined with claims of mate recognition by EOD waveform, the IDI pattern being irrelevant (e.g., review by Hopkins, 1988). In the present author's opinion (e.g., Kramer, 1985a, $1990 \mathrm{~b}$ ), most of these reports suffer from unresolved questions of systematics, lack an intraspecific variability analysis, or offer only insufficiently controlled behavioral experiments because of difficult conditions in the wild. Also, the confounding effect of water conductivity on EOD waveform has only rarely been controlled for (Bratton and Kramer, 1988; Kramer and Kuhn, 1993).

An interesting new finding in G. petersii, obtained on the day of their importation by a commercial dealer to New York, NY, is that of Landsman (1993). He observed EODs of statistically longer duration in males compared to females only in fish imported in June, but not May or October. May was the prerainy season, June the rainy breeding season, and October the postrainy season in the Nigerian origin of the fish in 1988. However, commercially imported fish coming from origins impossible to verify (except perhaps in a very gross manner), after a journey the duration and stress of which (Landsman et al., 1987; Landsman, 1991) cannot be assessed by a temperate zone customer, only allow limited conclusions concerning questions of intraspecific variability and sexual dimorphism. If these doubts may all be disregarded, then this result may indicate a seasonal EOD difference in the two sexes of a mormyrid. This could also explain the finding of no EOD sex difference in $G$. petersii by Kramer and Westby (1985), who studied a nonbreeding laboratory population. 
We now have in $G$. petersii nearly all possible suggestions: male EODs were found to be (1) of shorter duration than those of females (Landsman et al., 1987); (2) of longer duration compared to those of females for fish imported during the rainy season, although neither the rain nor the precise origin of the fish were confirmed by the personal presence of the scientist (Landsman, 1993); and (3) in spite of a considerable interindividual variability in both sexes, male EODs were not systematically different from female EODs (Kramer and Westby, 1985). This confusing situation should, perhaps, lead us to (a) consider the question still open and (b) choose a different strategy of studying the question before publishing still another possibility.

The groundwork necessary for establishing variability data for the EOD of each species will be laid only by studying breeding laboratory populations (the only example being $P$. isidori), by carefully controlled ethological experiments, and by systematically/taxonomically oriented field studies, such as those by Crawford and Hopkins (1989) or Moller and Brown (1990).

In the first of these two studies, EODs slightly, but systematically, different from those of Mormyrus rume led to the discovery of a new sibling species, Mormyrus subundulatus, which has subsequently been defined also morphologically. The opposite case is given by the second study (Moller and Brown, 1990). In a collection of mormyrids clearly determined as Mormyrops curviceps on anatomical grounds, all caught at the same place in West Africa, two markedly different EODs were observed. An individual had either short EODs of about $0.5 \mathrm{~ms}$ duration or long EODs of about $1.6 \mathrm{~ms}$ duration and, most unusually, a reversed polarity of phases (the first main phase being head-negative); this was unrelated to sex or developmental stage. It is as yet unclear whether these totally different EOD waveforms betray the existence of a pair of sibling species that are morphologically so similar that they passed undetected until now, or two EOD morphs within a single species. Much work will be necessary to clarify the systematic status of these morphs and the behavioral significance of their markedly distinct EOD waveforms.

A recently collected population of Marcusenius macrolepidotus from the Sabi river, Eastern Transvaal, South Africa, does show markedly distinct EOD durations between mature males (1.3-1.4 ms) and females (about $0.6 \mathrm{~ms}$ ). Fish were collected by the scientists themselves (from the 22nd to 25th of September, 1993, that is, during the spring season shortly before raining), and studied for their EOD waveform immediately after capture in the original river water (Kramer and Skelton, in preparation). I feel this case is a safe example for sexual dimorphism of EOD waveform in a mormyrid. 


\section{Constancy of the Mormyrid EOD Waveform in a VARIABLE ENVIRONMENT BY IMPEDANCE MATCHING}

In tropical African rivers and streams, water conductivity varies both geographically and seasonally, from a high of about $150 \mu \mathrm{S} / \mathrm{cm}$ (or a resistivity of $7 \mathrm{k} \Omega \cdot \mathrm{cm}$ ) to a low of about $5 \mu \mathrm{S} / \mathrm{cm}$ (or a resistivity of $200 \mathrm{k} \Omega \cdot \mathrm{cm}$, which is almost the equivalent of deionized water). Variations in conductivity may severely affect the EOD waveform as the following examples show.

It has long been known that the second, head-negative phase of the discharge of $G$. petersii (Fig. 2, left) decreases in amplitude and increases in duration when the resistance of the medium passes beyond a certain threshold, as is the case, for example, in deionized water (Harder et al., 1964; Bell et al., 1976), but also in tropical fresh waters of low conductivity. These biophysical observations confirmed the theory of the electrophysiology of the mormyrid electric organ, which states that the second phase of the discharge is electrically evoked by the current associated with the first, head-positive phase (Bennett, 1971a).

However, a conductivity-dependent change of EOD waveform not only is of biophysical and electrophysiological interest but also has implications for electrocommunication. This was studied in $P$. isidori and Petrocephalus bovei, the EOD waveforms of which were shown to depend strongly on water conductivity within the ecologically relevant range (Bratton and Kramer, 1988); Figs. 7B and 7E show this phenomenon in two other species. In the case of $P$. isidori with its great intraspecific EOD waveform variability, this dependence on an unstable ecological factor appeared to make the EOD waveform still more unreliable as an indicator of sex or of individual identity during communication.

However, this conclusion of Bratton and Kramer (1988) was premature for the long term. It is true that we do not find in mormyrids the kind of "anatomical" impedance matching that we find in strongly electric fish like the marine electric ray, as compared with, for example, the freshwater electric eel. The eel's organ has a low-current-high-voltage output and consists of a few columns that are very long (each composed of about 6000 electrocytes arranged in series). Thus the eel is very well adapted to generate dangerous shocks in a medium of very high resistance. By contrast, the ray's electric organ discharges into a medium of very low resistance and consequently has a high-current-low-voltage output, generated by many short columns arranged in parallel. Therefore, the ray is also well adapted to its entirely different habitat and effectively immobilizes its prey by electroshocks. The electric organs of the weakly electric mormyrids, however, are unlike those of both fishes: four short columns, located 

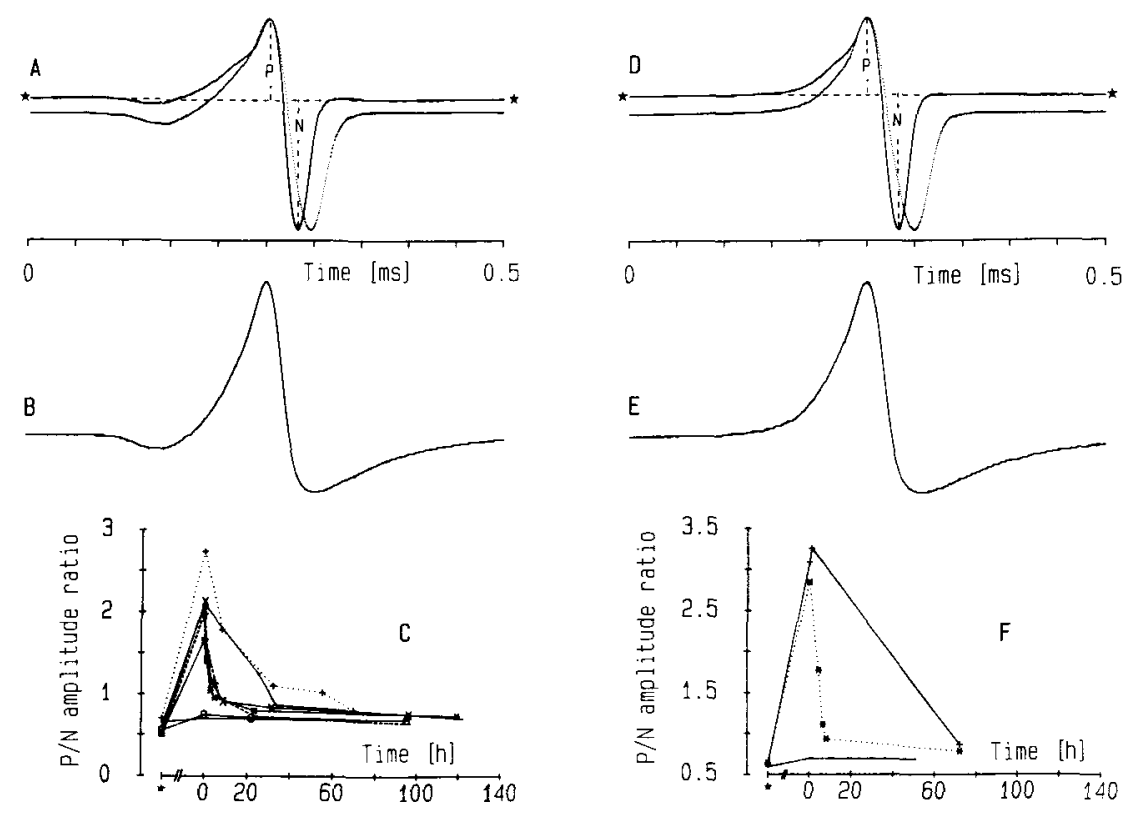

Fig. 7. Electric organ discharge waveforms of two mormyrids under high and low water conductivity. Left: Campylomormyrus tamandua $(N=7)$; right: $C$. rhynchophorus $(N=3)$. Oscillograms were recorded at $2 \mathrm{MHz}$ digitization rate. (A,D with *) Both species' EODs were recorded at $150 \mu \mathrm{S} / \mathrm{cm}$ conductivity before the experiment. When fish were transferred into water of only $10 \mu \mathrm{S} / \mathrm{cm}$, the head-negative $\mathrm{N}$ phase was almost abolished (B,E). However, after about 2 days in the low-conductivity water the original waveform had almost recovered ( $A, D$, no asterisks). (C,F) The time course of change for the $P / N$ amplitude ratio for both species: after an initial steep rise associated with the transfer of the fish into water of low conductivity ( $\mathrm{at} \mathrm{O} \mathrm{hr}$ ) found in most fish, $\mathrm{P} / \mathrm{N}$ ratios receded to values close to normal after about 2 days. The waveform differences as shown in A and D were permanent $(>3$ months); that is, the waveform recovery was incomplete, and conductivity had a graded, permanent effect on the EOD waveform at least up to $70 \mu \mathrm{S} / \mathrm{cm}$. From Kramer and Kuhn (1993).

in the caudal peduncle of the tail fin, are composed of a rather low and constant number of electrocytes (depending on the species, about 100).

In spite of the anatomically fixed situation, the electric organs of two mormyrid species (Campylomormyrus tamandua and Campylomormyrus rhynchophorus) studied were clearly able to match their biophysical properties as a current and voltage source to the experimentally imposed impedance changes of the surrounding medium (Fig. 7; Kramer and Kuhn, 1993). The matching process required about 2 days when the water conductivity change was very strong. After adaptation to the new conductivity, the original waveform was largely but not quite restored. 
The matching process itself is as yet unknown but might be triggered by a hormonally mediated, osmotic stress reaction (Mazeaud and Mazeaud, 1981; reviews in Rankin and Jensen, 1993), which could, in turn, initiate several cytological and biochemical responses in the electrocytes (e.g., the synthesis of membrane channel proteins; reviewed in Mills and Zakon, 1991). The synthesis of sodium channel proteins and their processing to the mature form requires $24 \mathrm{hr}$ in the electric eel's electrocytes (Thornhill and Levinson, 1987), which agrees well with the time course of the behaviorally observed impedance matching in the electric organ of Campylomormyrus.

Because of the ability of the electric organ to adapt to water of a wide range of conductivities within about 2 days, we now believe that the potential information content of the EOD waveform as a mark of species or individual identity is not destroyed (although affected) by the ecologically caused variations of the physical properties of the communication channel (sensu Shannon and Weaver, 1949), that is, the water the fish live in.

It has been said that this variation was unimportant because fish that interact are swimming in the same water (Crawford, 1992), dismissing the arguments of Bratton and Kramer (1988) as to the confounding effect of conductivity. The observation that fish usually swim in water certainly is correct, but who knows whether $5 \mathrm{~min}$ ago it was the same water? There may be extreme variations between confluent tropical streams and rivers, an exemplum maximum being the Solimoes (Amazon) with its $70 \mu \mathrm{S} / \mathrm{cm}$ white water and the Rio Negro with its $15 \mu \mathrm{S} / \mathrm{cm}$ black water at their confluence near Manaus, Amazon (B. Kramer, personal observation), which mix only after several kilometers.

Recent evidence also shows that the other function of the electric system of mormyrids, active electrolocation, critically depends on the speciescharacteristic EOD waveform because the relevant electroreceptors, the mormyromasts with their anatomically and functionally specialized $\mathrm{A}$ and B receptor cells (Bell, 1990; Bell et al., 1989), are sensitive even to slight EOD waveform distortions (von der Emde and Bleckmann, 1992), such as occur during the active electrolocation of objects with a capacitive impedance component (von der Emde, 1990). It is not yet clear whether this sensitivity for EOD waveform changes, as locally induced by objects with a capacitive impedance component, is related to the remarkable ability of $P$. isidori to discriminate the individually variable EOD waveform of conspecifics (acting globally on a fish's receptor population).

Therefore, the recently discovered $M$. subundulatus (Crawford and Hopkins, 1989) might discriminate the EODs of members of its own species from those of its sympatric sibling species, $M$. rume, although their EOD waveforms differ only slightly. 


\section{Electrical Signaling in Gymnotiform Pulse Species}

Weakly electric pulse fishes within the South American order Gymnotiformes comprise the families Hypopomidae, Rhamphichthyidae, and Gymnotidae [For a brief systematic overview, including treatment of the monospecific electric eel of the family Electrophoridae, which is both strongly and weakly electric, and not dealt with here, see the review by Kramer (1990b).]

The discharge activity of these pulse fishes is in some ways similar to, but also markedly different from, that of mormyrids. It is similar in that most species (see the following for exceptions) increase their discharge rate when disturbed by, for example, a vibratory, an acoustic, or an electrical stimulus. In addition, in the few species investigated, an attack on a conspecific is usually, but not always, accompanied by an EOD display reminiscent of that shown by an aggressive mormyrid: a sharp increase of EOD rate followed by a slower decrease (SID; e.g., in Gymnotus carapo; Black-Cleworth, 1970; Westby, 1975a). During a decrease the discharge rate "dies away" from the peak rate (up to $250 \mathrm{pps}$ in G. carapo) to the resting discharge rate level (around $40 \mathrm{pps}$ ), following a time course resembling an exponential decay (unlike mormyrids).

The signaling in gymnotiform pulse species differs from that of mormyrids mainly in three ways. First, gymnotiform EOD pulses tend to be of longer duration (most species' EODs are within 1-4.4 ms) compared to those of most mormyrids. Second, the SID display is only statistically associated with attack behavior and, in addition, is rather unspecific, accompanying various other behaviors or behavioral states as well, for example, in G. carapo, predatory attacks, being prodded by a stick, or being attacked by a conspecific. Mormyrids, however, broadcast specific EOD displays as an obligatory part of a variety of different behaviors or behavioral states. Third, whereas a mormyrid's EOD activity very often displays a rhythm, that is, a pattern of intervals of different lengths in a characteristic sequence that accompanies specific behaviors (see Section IV), in gymnotiform pulse species there is no such pattern (except the tonic change during discharge rate increase or decrease, which may, however, be very rapid; e.g., in the "decrement burst" displayed by Hypopomus occidentalis, consisting of a few EODs of very high rate interspersed into the normal, on-going activity; Hagedorn (1988)]. In gymnotiform pulse species, inter-EOD intervals are usually of almost equal duration, varying only statistically about the mean (except when involved in some dramatic activity like attack). Usually this variation is quite narrow; for example, during "quiet" discharge periods of resting G. carapo, the standard deviation may be almost as low as $1 \%$ of the mean of 1000 inter-EOD intervals. 
Therefore, the term "buzzer" is much more appropriate for most gymnotiform pulse species, which also tend to discharge at higher rates, than for mormyrids (up to about 65 pps at rest during the day compared to less than $10 \mathrm{pps}$ in mormyrids).

By and large, EOD displays in gymnotiform pulse species like G. carapo seem to be limited to discharge rate increases, decreases, and brief stops or "breaks"; otherwise, the mean inter-EOD interval duration (or its reciprocal, the discharge rate) and its standard deviation characterize the EOD activity sufficiently. However, detailed EOD interaction maneuvers and sensitivity to the phase of a discharge cycle have also been reported (Westby, 1975b, 1979). The ethological significance is still unclear but a function relating to sensory physiology seems well founded.

Some gymnotiform pulse species (within the genera Hypopygus, Steatogenys, Rhamphichthys, and Hypopomus) are unlike other pulse species because they do not respond to any ordinary form of stimulation by a discharge rate change. With extreme regularity and at rather high rates for pulse species, they drone on like a quartz clock; the standard deviation of 1000 inter-EOD intervals is only $0.3 \%$ of the mean. Only specific electrical stimulation will make them slightly shift their rate. These fishes' electrical behavior resembles that of gymnotiform wave species (see the following), except that they discharge in the form of pulses. Apart from their electrical "jamming avoidance" behavior to artificial stimulation (Gottschalk and Scheich, 1979; Scheich et al., 1977; Heiligenberg, 1974, 1977; Heiligenberg et al., 1978a), the signaling of these fishes during different behaviors is unstudied.

Reproductive behavior in gymnotiform pulse species has not yet been studied in great detail either. Both Hypopomus occidentalis and Hypopomus pinnicaudatus emit EODs resembling single-cycle sinusoids, with the male EODs being of longer duration compared to those of females (Hagedorn and Carr, 1985; Hopkins et al., 1990). When female H. occidentalis were stimulated with trains of single-cycle sinusoidal pulses of male duration they gave more discharge rate responses ("decrement bursts"; Hagedorn, 1988) compared to under stimulation with pulses of shorter (female) duration (Shumway and Zelick, 1988). These authors suggest that females discriminate male from female EODs (or artificial pulses of appropriate duration) by their difference in spectral amplitudes: male EODs tend to have their spectral amplitude peak at lower frequencies than do females $(826.2 \pm 200.4 \mathrm{~Hz}$ versus $984.4 \pm 97.6 \mathrm{~Hz}$; Hagedorn and Carr, 1985).

Another interesting finding is the observation that the EOD duration in male $H$. occidentalis is quite plastic: winning or losing a territorial contest in a small aquarium is sufficient to increase or reduce, respectively, a 
male's EOD duration and amplitude within 2 days; a loser's EOD hence becomes more femalelike (Hagedorn and Zelick, 1989).

Individual recognition by EOD waveform has recently been shown in territorial $G$. carapo. The individuals differ somewhat in the waveform of their EOD pulse, similar to the variability observed in the mormyrid $P$. isidori, which also recognizes conspecifics individually by their EOD (see Section VI). When the prerecorded EOD pulse of a G. carapo, designated as "neighbor" who was removed for an experiment, was played back from an experimental fish's "incorrect" side, the fish attacked the dipole model used for playback significantly more often compared to a playback from the fish's "correct" side, that is, that neighbor's usual position with regard to the experimental fish (McGregor and Westby, 1992). The sensory mechanism of EOD waveform discrimination is still unknown, but the authors suggest a hypothetical scanning mechanism as presented in an earlier paper (Hopkins and Westby, 1986), although a simpler mechanism, such as the one proposed for $H$. occidentalis (see the foregoing), can also be imagined. It should be noted that in the mormyrid $P$. isidori, which also discriminates its conspecifics' individual EOD waveforms, a scan sampling mechanism can be excluded because of an EOD rate that is inherently too variable and unrelated to the stimulus pulse rate (Graff and Kramer, 1989, 1992).

\section{Electrical Signaling in Gymnotiform Wave Species}

\section{A. Frequency Modulations and Frequency Sensitivity}

Gymnotiform wave species comprise the families Sternopygidae (at least 11 species) and Apteronotidae (at least 25 species). The Sternopygidae with their myogenic electric organs usually discharge at lower frequencies than the Apteronotidae, which possess electric organs of neural origin (Bennett, 1971a; Bass, 1986). Although a few sternopygids discharge at frequencies far beyond those of any ordinary nerve or muscle (greater than $800 \mathrm{~Hz}$ ), certain apternotids go still higher (up to $1800 \mathrm{~Hz}$; Kramer, 1990b). The special adaptations making possible such high discharge frequencies are unstudied (except the observation that electric, i.e., fast, synapses abound in both the sensory and the motor pathways: Szabo, 1967; Waxman et al., 1972). Also the constancy of the discharge frequencies is unrivaled. In Apteronotus albifrons, the standard deviation of the mean EOD cycle, measured over a thousand cycles of about $1 \mathrm{~ms}$ duration, may be as low as $0.012 \%$ (or $0.14 \mu \mathrm{s}$ ) and was actually limited by the accuracy of the measurement (Bullock, 1970). Still lower values were observed in Eigenmannia (Kramer, 1987). 
These fishes only rarely modulate their frequency during the day but may do so frequently at night when fighting or courting. Eigenmannia males, for example, give series of brief interruptions ("chirps") at a rate between one per minute and five per second. A female will only spawn when a male has chirped at her site for at least one hour (Hagedorn and Heiligenberg, 1985). In response to mild attacks by the male she will raise her EOD frequency by a few to several hertz over a period of tens of seconds ("long rises"). Hopkins (1974) has studied these and other EOD frequency modulations. No detailed ethological study is yet available correlating discharge frequency displays with behavior, comparable to the studies in Gymnotus or the mormyrids.

A frequency modulation that can be evoked by artificial stimulation is the so-called "jamming avoidance response" (JAR). This response was discovered by Watanabe and Takeda (1963) and given its present name by Bullock et al. $(1972 \mathrm{a}, \mathrm{b})$. The neural mechanisms of perception and motor control are reviewed by Heiligenberg $(1988,1991)$. The JAR usually is an EOD frequency shift away from the frequency of a stimulus signal (e.g., a sine wave), if above threshold. The absolute detection threshold of a signal and the threshold for the JAR are identical, provided the stimulus frequency is sufficiently close to that of the fish (within about $\pm 20 \mathrm{~Hz}$ difference; reviewed in Kramer and Kaunzinger, 1991).

Traditionally the JAR has been seen as a fish's attempt to escape from a condition in which its active electrolocation performance is impaired. However, as argued by Kramer (1987), the experimental evidence is not particularly strong, given that stimulus intensities capable of interfering with a fish's electrolocation performance are unrealistically high (as determined by Heiligenberg, 1977). Another wave species from the same family that does not possess a JAR, Sternopygus, shows only an impairment of electrolocation at a stimulus strength 50 times that of its own near-field EOD intensity (Matsubara and Heiligenberg, 1978). This shows that electrolocation of an object, as sensed by a small, local population of electroreceptors, is not necessarily "jammed" by another fish's EOD acting globally on all the electroreceptors of a fish.

An observation that strongly suggests a function of the JAR in the context of social communication was the discovery of the sexual dimorphism of the JAR (Kramer, 1987). Adult males are almost unresponsive to jamming stimuli, whereas females only lower their discharge frequencies to stimuli of higher frequency than their own discharge and will not respond to stimuli that should evoke a frequency increase. Juveniles show a high degree of interindividual variability and may respond in both directions, although asymmetrically (i.e., stronger for an identical frequency difference of one sign compared to that of the opposite sign). 
The hypothesis of a communication function of the JAR implies that, instead of trying to minimize the "jamming" or disrupting effect of another fish's signal on its own EOD, a fish would be trying to maximize (or optimize) the modulating effect of that signal on its own EOD in order to improve its own resolution for analyzing other fishes' signals. Information of interest for a fish displaying a JAR would be the frequencies of these signals and their waveforms, because both contain relevant information as to the age and sex of the sender (see next section). Also, by better distinguishing the various signals that a fish receives, it may obtain a better idea of the spatial structure of the group of which it forms a part. The sensory mechanism for EOD waveform analysis, as proposed by Kramer and Otto (1991), needs the JAR if the frequencies of two fish are too close (see next section).

How good is a fish's frequency and intensity discrimination? Trained Eigenmannia received a food reward when they detected an alternation in a sequence of sine wave bursts (repeated at 2 per second, with $150 \mathrm{~ms}$ silence between the bursts), either in frequency or in intensity. Close to a fish's discharge frequency, and at a 30-dB sensation level, fish discriminated frequency differences as small as $0.52 \mathrm{~Hz}$ and intensity differences as small as $0.56 \mathrm{~dB}$ (Kramer and Kaunzinger, 1991). A frequency difference threshold of about $0.5 \mathrm{~Hz}$ corresponds well to the minimum frequency difference $(0.6 \mathrm{~Hz})$ necessary to evoke only JARs of one sign and not the other about a fish's "decision" point, which usually is close to $0 \mathrm{~Hz}$ difference (stimuli were not frequency-clamped to a fish's EOD; Kramer, 1987).

At stimulus frequencies higher or lower than a fish's own discharge frequency, the frequency discrimination of Eigenmannia (and also intensity discrimination) declined steeply (Fig. 8, left). However, compared to other acoustico-lateral senses in lower vertebrates for which difference thresholds are known (i.e., sensitivity to water surface waves and in audition), the electrosensory frequency difference threshold of Eigenmannia is exceptionally high and in the range of the frequency difference thresholds for hearing in the most sensitive vertebrates with a cochlea (e.g., the human; Fig. 8, right). This is especially true for frequencies close to or above a fish's EOD frequency. The frequency modulations occurring in social behavior are all considerably above the detection limit of Eigenmannia (Hopkins, 1974; Hagedorn and Heiligenberg, 1985; see also Kramer, 1987).

The superior electrosensory acuity of Eigenmannia is the result of an ingenious simultaneous comparison of a fish's own signal with the stimulus, using the physics of the beating superimposition signal (for clear descriptions of the physics, see Scheich, 1977; Heiligenberg et al., 1987b; 

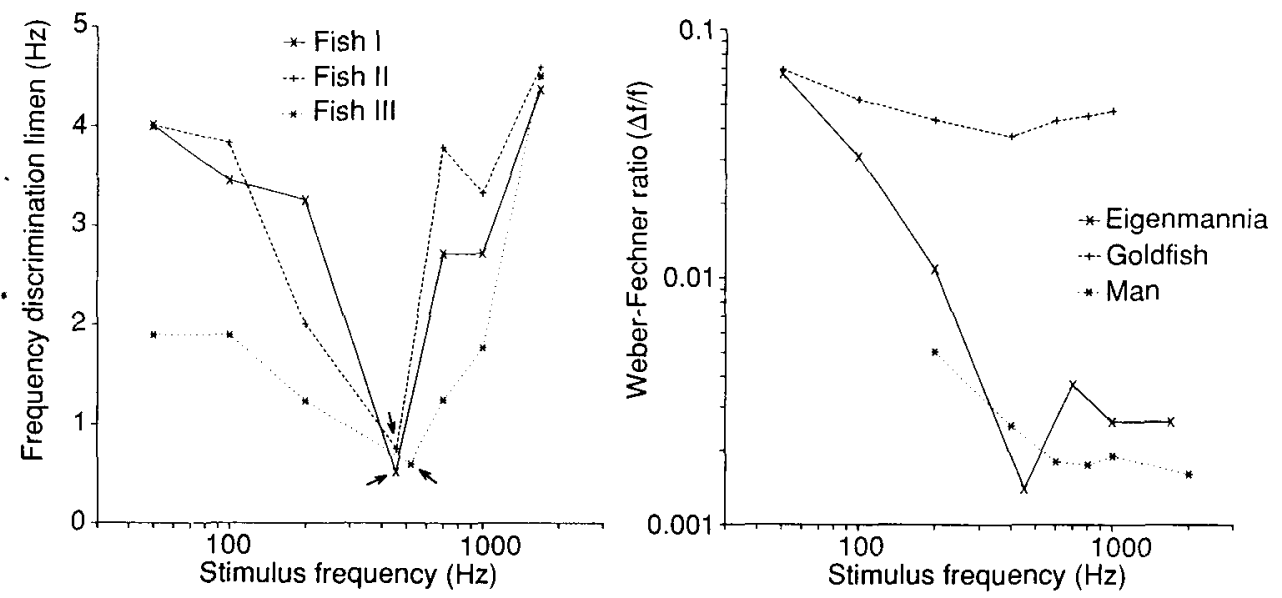

FIG. 8. Electrosensory frequency discrimination (left) in the wave fish Eigenmannia, as compared with auditory frequency discrimination in the goldfish and the human (right). Left: Close to a fish's discharge frequency, lowest frequency difference thresholds were found, steeply rising to both lower and higher frequencies. However, expressed as a fraction of the respective stimulus frequency (Weber-Fechner ratio, $\Delta f / f$; right), these thresholds did not rise much above a fish's $(N=3)$ discharge frequency. The electrosensory frequency discrimination of Eigenmannia is exceedingly acute as compared with the hearing difference thresholds of even one of the most sensitive mammals, the human; the goldfish is much less sensitive. For the human the most "flattering" data that could be found in the literature were used (Wier et al., 1977), although not shared by other authorities (e.g., Zwicker, 1982). The goldfish data are from Fay (1970), as also given in Fay (1988). From Kramer and Kaunzinger (1991).

for natural EOD beats, see Kramer and Otto, 1991). The fish's electrosensory system is specialized to detect minute modulations of its own EOD by a stimulus signal in both amplitude and phase.

In an especially clear way, this has recently been demonstrated in Sternopygus, which is much less sensitive to stimuli of exactly its own frequency, or integer multiples thereof, compared to stimulus frequencies only slightly different from one of these frequencies (Fleishman et al., 1992). This is because stimuli of exactly the frequency of one of the harmonics of the EOD (including its fundamental) do not beat against a fish's EOD. Because Sternopygus does not possess a JAR, frequency identity of a stimulus wave with its EOD (or one of its higher harmonics) may be maintained for a short period of time without the need for frequency-clamping. A similar result was obtained in Eigenmannia using a frequency-clamped stimulus (Kaunzinger and Kramer, 1993).

Unlike other vertebrates, Eigenmannia and similar fish need not deal with stimuli as they occur, varying over many orders of magnitude in both 
frequency and intensity, but face a small range of variation only of the superimposition signal, which allows these fish to specialize in a high difference sensitivity.

\section{B. Sensitivity for EOD WAVEForms}

Eigenmannia has a sexually dimorphic EOD waveform: females and juveniles show a rather sinusoidal waveform with the positive half-waves being only slightly shorter than the negative ones, whereas adult males have much more asymmetric waveforms with longer negative half-waves (see Fig. 10). Fish discriminate these waveforms in playback experiments, with neither intensity nor frequency being factors (Kramer and Zupanc, 1986; Kramer and Otto, 1988; for method, see Kramer and Weymann, 1987).

The natural EOD, in addition to varying in waveform, also varies in the composition of spectral amplitudes, that is, in its harmonic content (the harmonic content of a voice or a musical instrument determines its timbre). Male EODs have much stronger higher harmonics than the EODs of females or juveniles (Kramer, 1985a); therefore, fish could in theory, and more conventionally, discriminate the sexually dimorphic EODs by their difference in harmonic content rather than in waveform. (For the human, an audio playback of the female EOD has a "dull" timbre, not unlike a flute, whereas male EODs have a more brilliant quality, similar to that of a violin, the sound of which is also rich in overtones.)

Only recently has it become clear that Eigenmannia is able to discriminate (artificially generated) signals of different waveforms that have identical amplitude spectra, that is, no difference in harmonic content. These signals, when made audible, are therefore indistinguishable for the human.

To test for a "pure" waveform (time domain) sensitivity (as opposed to sensitivity for the harmonic content of a signal, which is in the frequency domain), phase differences between the harmonics of a signal were introduced. This changes a signal's waveform but does not affect its amplitude spectrum (Fig. 9) and is not detected by the auditory system of the human.

Trained Eigenmannia clearly detected a difference of $90^{\circ}$ in phase relationship between the two harmonics of a pair of signals as shown in Fig. 9, and much smaller phase differences as well. The threshold phase shift is below $22^{\circ}$, causing a signal to change its waveform only slightly (Kramer and Teubl, in press). A mechanism for this new sensory capacity was proposed by Kramer and Otto (1991). The electroreceptors on a fish's right and left body sides face opposite polarities of a distant stimulus source (Fig. 10). Because electroreceptors are polarity-sensitive, the stimulus signal is added to or subtracted from the fish's own EOD, according 

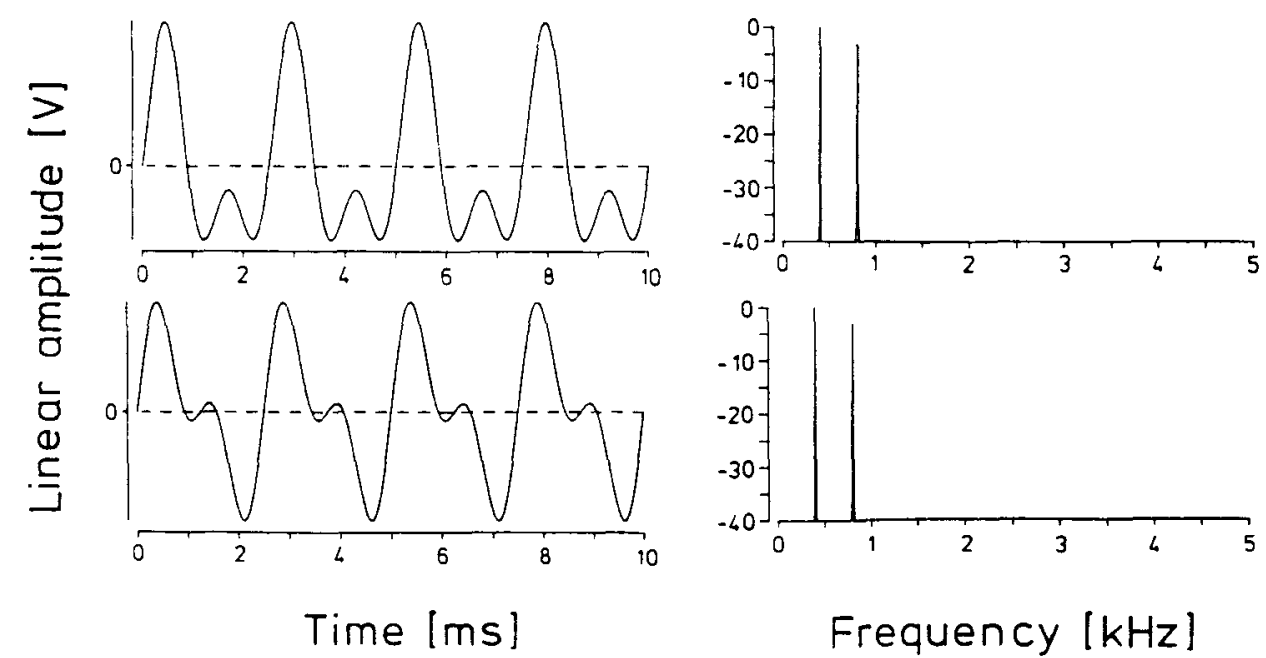

FIG. 9. Artificially generated signal waveforms (left) that have an identical amplitude spectrum (right). These electrical signals, played at intensities and frequencies typical for Eigenmannia, are discriminated by trained, food-rewarded fish, although acoustical presentations are indistinguishable for the human. The signals are composed of only two sine waves, the fundamental frequency, $f_{1}$, and its harmonic of two times that frequency, $f_{2}$. Though the phase difference, relative to the amplitude peaks of both sine wave components, is $0^{\circ}$ for the upper waveform, it is a maximum $90^{\circ}(\pi / 2)$ for the lower waveform. From Kramer and Otto (1991).

to a receptor's location. Therefore, a fish's right and left populations of receptors receive different superimposition signals, with phase differences between the zero-crossings (Fig. 11).

A sensory circuit has been found in a specialized part of the Eigenmannia midbrain (the torus semicircularis) performing a left-right (or front-rear) comparison of afferences from the T-electroreceptors, which preserve precise temporal information about such phase differences (Carr, 1990). This comparison should enable a fish to reconstruct the form of a wave signal modulating its own EOD; the ability to do so, even in the absence of any spectral amplitude cues, has been proven (see earlier).

A fundamental drawback in communication for all wave fishes, as compared with pulse fishes, is the impossibility of receiving their conspecifics' EOD waves in pure form (nor their own, for that matter). This drawback has elegantly been turned into an advantage. First, by scanning through another fish's EOD waveform by beat analysis, fish gain time: a fish may choose whichever duration of a beat cycle it finds convenient by changing its frequency (e.g., by displaying a JAR; see previous section). A JAR 


\section{A}
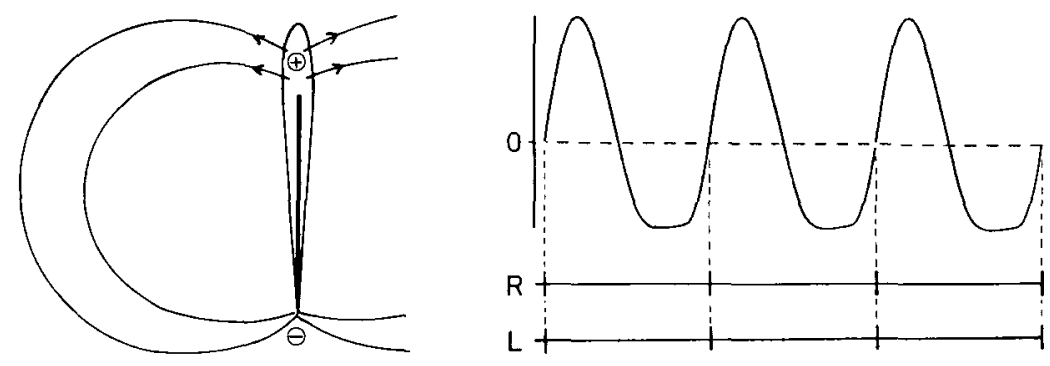

B
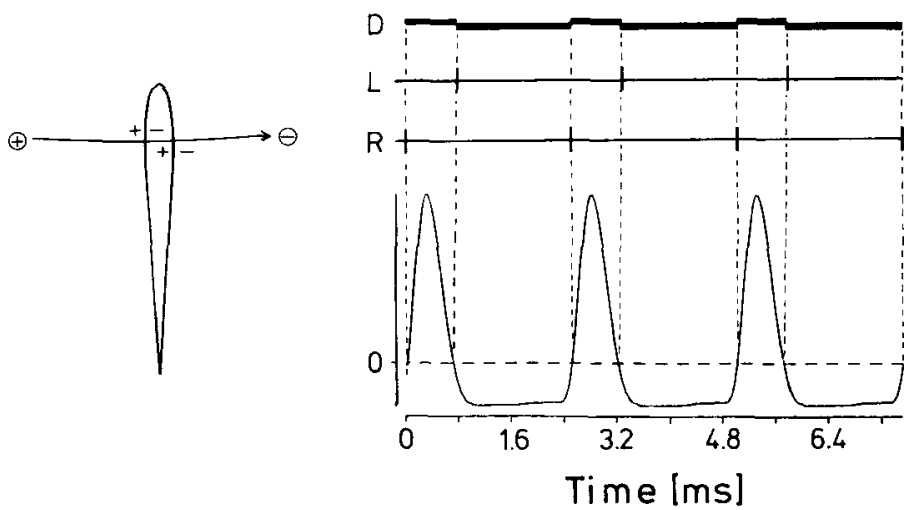

FIG. 10. Schematic representation of the polarity (left) of electric organ discharges of the wave type, as experienced by a fish's electroreceptors, and their afferent responses ( $\mathrm{T}$ receptors, right). (A) An Eigenmannia electric organ (bar) generates a dipole field that has the same polarity for its left and right side T-electroreceptors in the fish's skin, which therefore fire in synchrony (shown for a female EOD waveform; $R$, right; $L$, left side electroreceptors). (B) However, for the EOD of a distant fish (as an example, a male EOD waveform is chosen), the electroreceptors of the right and left body side fire in alternation, because they "see" the signal with opposite polarities. A male EOD would be represented by a short-long pattern of difference intervals for the T-afferences (D), whereas a female EOD would be represented by almost equal difference intervals. In reality, both fields (A and B) are superimposed, but the basic idea still holds (see Fig. 11), and a neural circuit for the comparison of right/left time disparities has been proposed (Carr, 1990). From Kramer and Otto (1991).

usually leads to beat cycles between $1 / 3$ and $1 / 7 \mathrm{~s}$, or about 100 times an EOD cycle (of about $2.5 \mathrm{~ms}$ ).

Second, for the reconstruction of a stimulus waveform modulating a fish's own discharge from its T-receptor afferences there has probably been a preexisting central neural circuit that only had to change its function within the acoustico-lateral senses. A circuit for the detection of right/ 

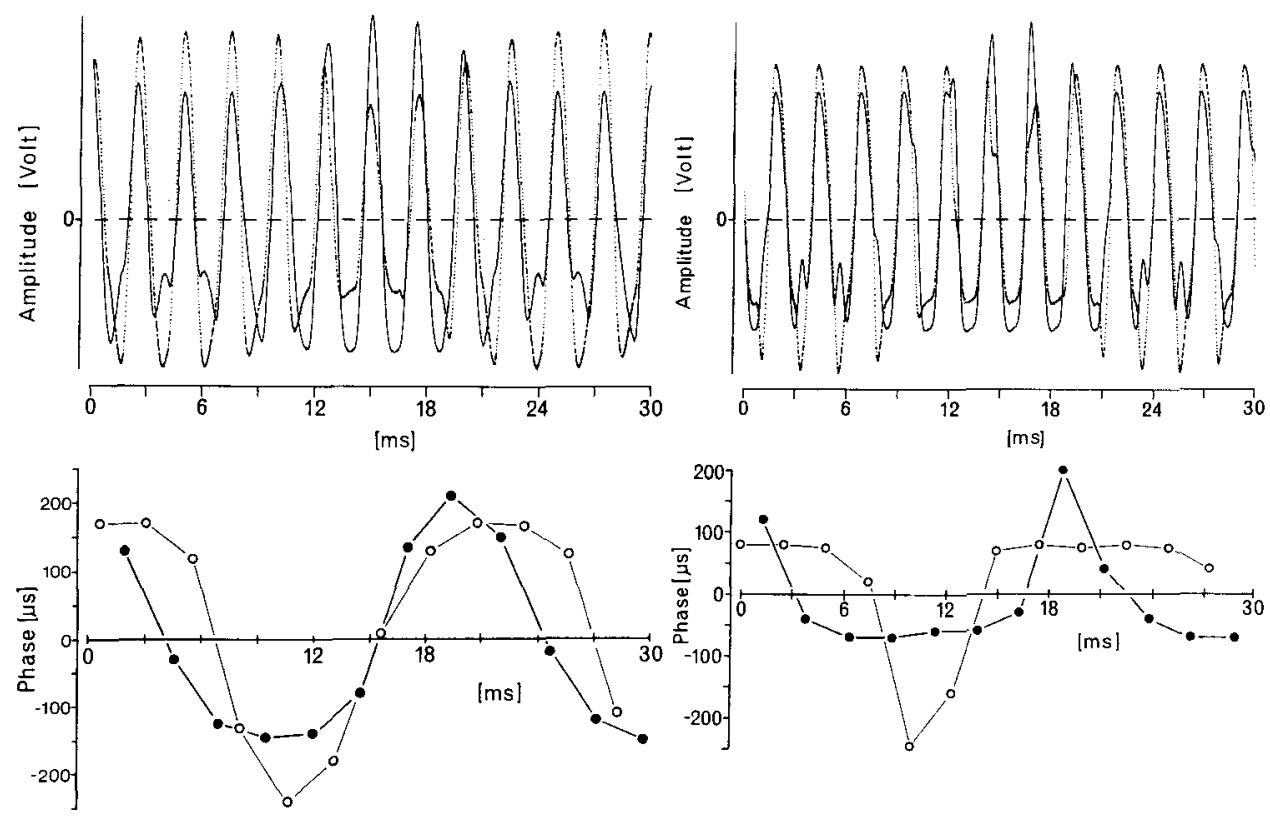

FIG. 11. An Eigenmannia female's own EOD (of $400 \mathrm{~Hz}$ and $100 \%$ amplitude) is superimposed by a conspecific's EOD (of $450 \mathrm{~Hz}$ and $30 \%$ amplitude). Left: the conspecific is another female; right: the conspecific is a male. Because of the frequency difference of $50 \mathrm{~Hz}$ chosen in this electronically generated example, a full beat period is only $20 \mathrm{~ms}$ (centered in both cases). Top: the superimposition is either additive (solid line) or subtractive (dotted line), as experienced by the fish's left and right side electroreceptors (see Fig. 10), depending on the fishes' relative position. Note that in both cases (left and right graphs) small time disparities about the zero-crossings occur. Bottom: these zero-crossing time disparities are plotted on an expanded scale (as phase in microseconds on the ordinate). The time functions of these right-left side phase differences correspond to the waveforms superimposing a fish's own signal (which serves as a "carrier" signal), that is, to a female EOD (left) and to a male EOD (right). The reconstruction of the waveform modulating a fish's own EOD seems to occur centrally from T-receptor afferences (in the midbrain; Carr, 1990). From Kramer and Otto (1991).

left side time disparities of sound signals is probably present in all vertebrates and underlies their directional hearing. The human, and still more so the barn owl, detects time disparities with an exceedingly high precision in the microsecond range; in the barn owl's brain the neural circuit has been described in great detail (see Section I).

The other class of high-frequency tuberous electroreceptors, the amplitude-sensitive P-receptors, only increase or decrease their probability of firing with the amplitude of the beat envelope. Because no detailed phase relationship to the stimulus is known, it is difficult to imagine that 
P-receptors could provide the information that the brain needs to reconstruct the waveform of a stimulus modulating a fish's EOD.

\section{The "So What?" Question}

All the foregoing research on (nearly) invisible creatures that live in some of the most remote habitats and communicate in a way that cannot be felt nor observed by the human (except in a very indirect way) may be very fine-but what is it good for? Different people may find different answers to this question. Without going into detail I will indicate a few points that I personally find of interest.

Weakly electric fishes are a good example for demonstrating that in order to make progress in answering a specifically behavioral question, like that of electrocommunication or electrolocation, more general biological and evolutionary problems have to be solved first. However, without the initial behavioral work (e.g., that of Lissmann, 1958; Lissmann and Machin, 1958) we would not have seen the problem, or much less of it. Therefore, the continuous interplay of both is necessary for making progress.

One of the most difficult problems for Darwin's theory of evolution (Darwin, 1859), even in its modern form, has been the question of how transitional traits can evolve and exist when they do not convey a selective advantage to their bearer. Among many other examples, Darwin considered the problem of the evolution of strongly electric fishes (he did not know of weakly electric ones). Today we know that weak electric organs need not be useless; on the contrary, in terms of species numbers, weakly electric teleosts have been much more successful than their strongly electric cousins. A weak electric organ that forms part of a sophisticated intelligence system represents an adaptive peak totally different from a strong organ that functions as an electric "club" (although admittedly an "intelligent" one, simultaneously acting in a volume of water surrounding a fish). This may teach us to be careful before declaring any organ or structure "useless."

A new sensory-motor system specifically dedicated to the electric modality opens up a whole new world and represents an enormous challenge for the zoologist. It also offers a host of research opportunities. Two examples may illustrate this point. (1) The question of how sensory systems deal with the stimulation due to an animal's own action, or reafference, has been studied especially successfully in electric fishes, more so than in any other system I know of (Bell and Szabo, 1986; Bell, 1986, 1989). (2) Vertebrate hair cells, like the sensory cells in our inner ear, are difficult to access and to study. Electric fishes have very similar cells, the 
electroreceptors, exposed in their skin. A number of electrophysiological and behavioral studies have profited from this situation and shown an exquisite sensitivity to the fine detail of stimuli, phase sensitivity, etc., that could not have been imagined previously. Its role in behavior is only beginning to be studied.

\section{Summary}

Teleost freshwater fishes of the orders Mormyriformes (the elephantfishes plus Gymnarchus from Africa) and Gymnotiformes (the knifefishes from South America) are both electrogenic and electroreceptive. These fishes' electric system has a motor part, the electric organ, and a sensory part, the cutaneous electroreceptors that project to large, specialized brain areas. The electric systems of both groups of fishes, although evolved independently, are adapted to the same two functions, nocturnal electrolocation and communication.

Weakly electric fishes discharge their electric organs in a pulselike or in a wavelike fashion ("buzzers" and "hummers," respectively). Whether a species is a hummer or a buzzer does not appear to be correlated with ecology but is strongly linked to phylogeny. There are representatives of both discharge types on both continents where these fishes are found.

The elephantfishes (Mormyridae, about 200 species) are, apparently, all pulse fishes, whereas the related, monospecific Gymnarchus (Gymnarchidae) is the only known African wave fish. There are five families of South American knifefishes, with the majority of the 70 or so species being hummers, usually discharging at extremely constant frequencies (about $50-1800 \mathrm{~Hz}$ ).

The sensory mechanisms of social communication, as studied by behavioral means, are reviewed in this chapter with the question of mechanisms of reproductive isolation in mind. The chapter focuses on the electric organ discharge as the basic communication unit, and on the frequency, repetition rate, or temporal patterns of discharges.

In both wave and pulse fishes the frequencies or repetition rates of discharges are not usually species-specific but are species-characteristic, because of more or less broad overlap between two or more species (depending on the local community of species). Electrosensory discrimination thresholds for frequency and intensity are unusually low in a wave fish, lower by far than those for other acoustico-lateral senses of aquatic lower vertebrates, rivaling the discrimination thresholds for audition in the most sensitive mammals (e.g., the human). A similar conclusion applies for the pulse rate sensitivity of a mormyrid.

Species specificity becomes apparent when more information about the 
discharge activity is considered. In the case of pulse fishes, especially mormyrids, this comprises temporal patterns of discharges, which also vary greatly according to behavioral context (like aggression, escape, courtship, feeding, etc.); these fishes have an interdischarge interval code of communication. In the case of wave fishes, various types of frequency modulations and brief, repetitive discharge stops occur. Also, wave fishes may engage in "phase coupling" and "jamming avoidance," maneuvers that involve precise interaction with another fish's discharges. The degree of species specificity of a fish's discharge activity is usually enhanced by features of the waveform of a single discharge; this is true in both pulse and wave fishes. Usually there is considerable intraspecific variability of discharge waveforms, and there are also examples of sexual dimorphism.

At least a few species can discriminate the individually variable pulse or wave discharge waveforms of their species. In a wave fish, a sensory mechanism based on the temporal analysis of beat patterns can explain the observed results. This new sensory capacity detects the phase modulation within a beat, which always occurs when the wave discharges of two fish mix in the water. In pulse fishes, several hypothetical sensory mechanisms for the discrimination of intraspecific pulse waveforms have been proposed but it is not yet clear which is generally involved. In any case, the sensitivity of weakly electric fishes to the fine detail of their discharges shows that the electrosensory world is much more colorful than could be imagined until recently.

\section{References}

Alerstam, T. (1990). "Bird Migration." Cambridge Univ. Press, Cambridge.

Bass, A. H. (1986). Electric organs revisited: Evolution of a vertebrate communication and orientation organ. In "Electroreception" (T. H. Bullock and W. Heiligenberg, eds.), pp. 13-70. Wiley, New York.

Bastian, J. (1986). Electrolocation: Behavior, anatomy and physiology. In "Electroreception" (T. H. Bullock and W. Heiligenberg, eds.), pp. 577-612. Wiley, New York.

Bauer, R. (1972). High electrical discharge frequency during aggressive behaviour in a mormyrid fish. Gnathonemus petersii. Experientia 28, 669-670.

Bauer, R. (1974). Electric organ discharge activity of resting and stimulated Gnathonemus petersii (Mormyridae). Behaviour 50, 306-323.

Bauer, R. and Kramer, B. (1974). Agonistic behaviour in mormyrid fish: Latency relationship between the electric discharges of Gnathonemus petersii and Mormyrus rume. Experientia 30, 51-52.

Bell, C. C. (1986). Electroreception in mormyrid fish. Central physiology. In "Electroreception" (T. H. Bullock and W. Heiligenberg, eds.), pp. 423-452. Wiley, New York.

Bell, C. C. (1989). Sensory coding and corollary discharge effects in mormyrid electric fish. J. Exp. Biol. 146, 229-253.

Bell, C. C. (1990). Mormyromast electroreceptor organs and their afferent fibers in mormyrid 
fish: III. Physiological differences between two morphological types of fibers. J. Neurophysiol. 63, 319-332.

Bell, C. C., and Szabo, T. (1986). Electroreception in mormyrid fish. Central anatomy. In "Electroreception"' (T. H. Bullock and W. Heiligenberg, eds.), pp. 375-421. Wiley, New York.

Bell, C. C., Myers, J. P., and Russell, C. J. (1974). Electric organ discharge patterns during dominance related behavior displays in Gnathonemus petersii. J. Comp. Physiol. A 92, 201-228.

Bell, C. C., Bradbury, J., and Russell, C. J. (1976). The electric organ of a mormyrid as a current and voltage source. J. Comp. Physiol. A 110, 65-88.

Bell, C. C., Zakon, H., and Finger, T. E. (1989). Mormyromast electroreceptor organs and their afferent fibers in mormyrid fish: I. morphology. J. Comp. Neurol. 286, 391-407.

Bennett, M. V. L. (1971a). Electric organs. In "Fish Physiology" (W. S. Hoar and D. J. Randall, eds.), Vol. 5, pp. 347-491. Academic Press, London and New York.

Bennett, M. V. L. (1971b). Electroreception. In "Fish Physiology" (W. S. Hoar and D. J. Randall, eds.), Vol. 5, pp. 493-574. Academic Press, London and New York.

Birkholz, J. (1969). Zufällige Nachzucht bei Petrocephalus bovei. Aquarium 3, 201-203.

Black-Cleworth, P. (1970). The role of electrical discharges in the non-reproductive social behaviour of Gymnotus carapo (Gymnotidae, Pisces). Anim. Behav. Monogr. 3(1), $1-77$.

Bratton, B. O., and Kramer, B. (1988). Intraspecific variability of the pulse-type discharges of the African electric fishes, Pollimyrus isidori and Petrocephalus bovei (Mormyridae, Teleostei), and their dependence on water conductivity. Exp. Biol. 47, 227-238.

Bratton, B. O., and Kramer, B. (1989). Patterns of the electric organ discharge during courtship and spawning in the mormyrid Pollimyrus isidori. Behav. Ecol. Sociobiol. 24, 349-368.

Bullock, T. H. (1970). The reliability of neurons. J. Gen. Physiol. 55, 565-584.

Bullock, T. H., and Heiligenberg, W., eds. (1986). "Electroreception." Wiley, New York.

Bullock, T. H., Hamstra, R. H., and Scheich, H. (1972a). The jamming avoidance response of high frequency electric fish. I. General features. J. Comp. Physiol. A 77, 1-22.

Bullock, T. H., Hamstra, R. H., and Scheich, H. (1972b). The jamming avoidance response of high frequency electric fish. II. Quantitative aspects. J. Comp. Physiol. A 77, 23-48.

Carr, C. E. (1990). Neuroethology of electric fish. Principles of coding and processing sensory information. BioScience 40, 259-267.

Crawford, J. D. (1991). Sex recognition by electric cues in a sound-producing mormyrid fish, Pollimyrus isidori. Brain Behav. Evol. 38, 20-38.

Crawford, J. D. (1992). Individual and sex specificity in the electric organ discharges of breeding mormyrid fish (Pollimyrus isidori). J. Exp. Biol. 164, 79-102.

Crawford, J. D., and Hopkins, C. D. (1989). Detection of a previously unrecognized mormyrid fish (Mormyrus subundulatus) by electric discharge characters. Cybium 13(4), 319-326.

Crawford, J. D., Hagedorn, M., and Hopkins, C. D. (1986). Acoustic communication in an electric fish, Pollimyrus isidori (Mormyridae). J. Comp. Physiol., A 159, 297-310.

Darwin, C. R. (1859). "On the Origin of Species by Means of Natural Selection, or the Preservation of Favoured Races in the Struggle for Life. Cambridge Univ. Press, New York (reprint, 1975).

Fay, R. R. (1970). Auditory frequency discrimination in the goldfish (Carassius auratus). J. Comp. Physiol. Psychol. 73, 175-180.

Fay, R. R. (1988). "Hearing in Vertebrates: A Psychophysics Databook." Hill-Fay Associates, Winnetka, IL. 
Finger, T. E., Bell, C. C., and Carr, C. E. (1986). Comparisons among electroreceptive teleosts: Why are electrosensory systems so similar? In "Electroreception" (T. H. Bullock and W. Heiligenberg, eds.), pp. 465-481. Wiley, New York.

Fisher, R. A. (1954). Evolution and bird sociality. In "Evolution as a Process" (J. Huxley, A. C. Hardy, and E. B. Ford, eds.), pp. 71-83. Allen \& Unwin, London.

FitzGerald, G. J. (1992). Filial cannibalism in fishes: Why do parents eat their offspring? Trends Ecol. Evol. 7, 7-10.

Fleishman, L. J., Zakon, H. H., and Lemon, W. C. (1992). Communication in the weakly electric fish Sternopygus macrurus. II. Behavioral test of conspecific EOD detection ability. J. Comp. Physiol. A 170, 349-356.

Freedman, E. G., Olyarchuk, J., Marchaterre, M. A., and Bass, A. H. (1989). A temporal analysis of testosterone-induced changes in electric organs and electric organ discharges of mormyrid fishes. J. Neurobiol. 20, 619-634.

Gottschalk, B. and Scheich, H. (1979). Phase sensitivity and phase coupling: Common mechanisms for communication behaviors in gymnotid wave and pulse species. Behav. Ecol. Sociobiol. 4, 395-408.

Graff, C. (1986). Signaux électriques et comportement social du poisson à faibles décharges, Marcusenius macrolepidotus (Mormyridae, Teleostei). Ph.D. Thesis, Univ. Paris-Sud Centre d'Orsay, Orsay.

Graff, C., and Kramer, B. (1989). Conditioned discrimination of the E.O.D. waveform by Pollimyrus isidori and Gnathonemus petersii. In "Neural Mechanisms of Behavior" ( J. Erber, R. Menzel, H. J. Pflüger, and D. Todt, eds.), p. 94. Thieme, Stuttgart.

Graff, C. and Kramer, B. (1992). Trained weakly-electric fishes Pollimyrus isidori and Gnathonemus petersii (Mormyridae, Telostei) discriminate between waveforms of electric pulse discharges. Ethology 90, 279-292.

Griffin, D. R. (1958). "Listening in the Dark." Yale Univ. Press, Princeton, N.J.

Hagedorn, M. (1988). Ecology and behavior of a pulse-type electric fish, Hypopomus occidentalis (Gymnotiformes, Hypopomidae), in a fresh water stream in Panama. Copeia 1988(2), 324-335.

Hagedorn, M., and Carr, C. E. (1985). Single electrocytes produce a sexually dimorphic signal in South American electric fish, Hypopomus occidentalis (Gymnotiformes, Hypopomidae). J. Comp. Physiol. A 156, 511-523.

Hagedorn, M., and Heiligenberg, W. (1985). Court and spark: Electric signals in the courtship and mating of gymnotoid fish. Anim. Behav. 33, 254-265.

Hagedorn, M., and Zelick, R. (1989). Relative dominance among males is expressed in the electric organ discharge characteristics of a weakly electric fish. Anim. Behav. 38, $520-525$.

Hagedorn, M., Womble, M., and Finger, T. E. (1990). Synodontid catfish: A new group of weakly electric fish. Behavior and anatomy. Brain Behav. Evol. 35, 268-277.

Harder, W., Schief, A., and Uhlemann, H. (1964). Zur Funktion des elektrischen Organs von Gnathonemus petersii (Gthr. 1862). J. Comp. Physiol. A 48, 302-311.

Hasler, A. C., and Scholz, A. T. (1983). "Olfactory Imprinting and Homing in Salmon." Springer-Verlag, Berlin.

Heiligenberg, W. (1974). Electrolocation and jamming avoidance in a Hypopygus (Rhamphichthyidae, Gymnotoidei), an electric fish with pulse-type discharge. J. Comp. Physiol. A 91, 223-240.

Heiligenberg, W. (1977). "Principles of Electrolocation and Jamming Avoidance in Electric Fish. Studies of Brain Function," Vol. 1. Springer-Verlag, Berlin and New York.

Heiligenberg, W. (1988). Neural mechanisms of perception and motor control in a weakly 
electric fish. In "Advances in the Study of Behavior" (P. Slater et al., eds.), vol. 18, pp. 73-98. Academic Press, San Diego, CA.

Heiligenberg, W. (1991). "Neural Nets in Electric Fish. MIT Press, Cambridge, MA.

Heiligenberg, W., Baker, C., and Bastian, J. (1978a). The jamming avoidance response in gymnotid pulse species: A mechanism to minimize the probability of pulse-train coincidence. J. Comp. Physiol. A 124, 211-224.

Heiligenberg, W., Baker, C., and Matsubara, J. (1978b). The jamming avoidance response in Eigenmannia revisited: The structure of a neural democracy. J. Comp. Physiol. A 127, 267-286.

Hennig, W. (1966). "Phylogenetic Systematics." Univ. of Illinois Press, Urbana.

Hopkins, C. D. (1974). Electric communication: Functions in the social behavior of Eigenmannia virescens. Behaviour 50, 270-305.

Hopkins, C. D. (1986). Behavior of Mormyridae. In "Electroreception" (T. H. Bullock and W. Heiligenberg, eds.), pp. 527-576. Wiley, New York.

Hopkins, C. D. (1988). Neuroethology of electric communication. Annu. Rev. Neurosci. 11, 497-535.

Hopkins, C. D., and Westby, G. W. M. (1986). Time domain processing of electric organ discharge waveforms by pulse-type electric fish. Brain Behav. Evol. 29, 77-104.

Hopkins, C. D., Comfort, N. C., Bastian, J., and Bass, A. H. (1990). Functional analysis of sexual dimorphism in an electric fish. Hypopomus pinnicaudatus, order Gymnotiformes. Brain Behav. Evol. 35, 350-367.

Kaunzinger, I., and Kramer, B. (1993). Schwebungen ("Jamming') sind notwendig für die Detektion sozialer Signale bei dem schwachelektrischen Messerfisch Eigenmannia. Verh. Dtsch. Zool. Ges. 86.1, 216.

Keeton, W. T. (1979). Avian orientation and navigation. Annu. Rev. Physiol. 41, 353-366.

Kirschbaum, F. (1975). Environmental factors control the periodical reproduction of tropical electric fish. Experientia 31, 1159-1160.

Kirschbaum, F. (1987). Reproduction and development of the weakly electric fish, Pollimyrus isidori (Mormyridae, Teleostei), in captivity. Environ. Biol. Fishes 20, 11-31.

Konishi, M. (1993). Listening with two ears. Sci. Am. 268(4), 34-41.

Kramer, B. (1974). Electric organ discharge interaction during interspecific agonistic behaviour in freely swimming mormyrid fish. A method to evaluate two (or more) simultaneous time series of events with a digital analyser. J. Comp. Physiol. A 93, 203-235.

Kramer, B. (1976). Flight-associated discharge pattern in a weakly electric fish, Gnathonemus petersii (Mormyridea, Teleostei). Behaviour 59, 88-95.

Kramer, B. (1978). Spontaneous discharge rhythms and social signalling in the weakly electric fish Pollimyrus isidori (Cuvier et Valenciennes) (Mormyridae, Teleostei). Behav. Ecol. Sociobiol. 4, 61-74.

Kramer, B. (1979). Electric and motor responses of the weakly electric fish, Gnathonemus petersii (Mormyridae), to play-back of social signals. Behav. Ecol. Sociobiol. 6, 67-79.

Kramer, B. (1985a). Jamming avoidance in the electric fish Eigenmannia: Harmonic analysis of sexually dimorphic waves. J. Exp. Biol. 119, 41-69.

Kramer, B. (1985b). Kommunikation mit elektrischen Signalen bei Fischen. In "Verhaltensbiologie" (D. Franck, ed.), pp. 273-277. Deutscher Taschenbuch-Verlag/Thieme, München and Stuttgart.

Kramer, B. (1987). The sexually dimorphic jamming avoidance response in the electric fish Eigenmannia (Teleostei, Gymnotiformes). J. Exp. Biol. 130, 39-62.

Kramer, B. (1990a). Sexual signals in electric fishes. Trends Ecol. Evol. 5, 247-250.

Kramer, B. (1990b). "Electrocommunication in Teleost Fishes: Behavior and Experiments." Springer-Verlag, Berlin. 
Kramer, B., and Bauer, R. (1976). Agonistic behaviour and electric signalling in a mormyrid fish, Gnathonemus petersii. Behav. Ecol. Sociobiol. 1, 45-61.

Kramer, B., and Heinrich, U. (1990). Discrimination of inter-pulse intervals. In "Electrocommunication in Teleost Fishes: Behavior and Experiments" (B. Kramer, ed.), pp. 170-177. Springer-Verlag, Berlin.

Kramer, B., and Kaunzinger, I. (1991). Electrosensory frequency and intensity discrimination in the wave-type electric fish Eigenmannia. J. Exp. Biol. 161, 43-59.

Kramer, B., and Kuhn, B. (1993). Electric signalling and impedance matching in a variable environment: The electric organ of a mormyrid fish actively adapts to changes in water conductivity. Naturwissenschaften 80, 43-46.

Kramer, B., and Lücker, H. (1990). Species recognition by EOD interval pattern. In "Electrocommunication in Teleost Fishes: Behavior and Experiments" (B. Kramer, ed.), pp. 157-170. Springer-Verlag, Berlin.

Kramer, B., and Otto, B. (1988). Female discharges are more electrifying: Spontaneous preference in the electric fish, Eigenmannia. Behav. Ecol. Sociobiol. 23, 55-60.

Kramer, B., and Otto, B. (1991). Waveform discrimination in the electric fish Eigenmannia: Sensitivity for the phase differences between the spectral components of a stimulus wave. J. Exp. Biol. 159, 1-22.

Kramer, B., and Teubl, H. (1994). Spectral phase sensitivity in a wave-type electric fish. Naturwissenschaften.

Kramer, B., and Westby, G. W. M. (1985). No sex difference in the waveform of the pulse type electric fish, Gnathonemus petersii (Mormyridae). Experientia 41, 1530-1531.

Kramer, B., and Weymann, D. (1987). A microprocessor system for the digital synthesis of pulsed or continuous discharges of electric fish (or animal vocalizations). Behav. Brain Res. 23, 167-174.

Kramer, B., and Zupanc, G. K. H. (1986). Conditioned discrimination of electric waves differing only in form and harmonic content in the electric fish, Eigenmannia. Naturwissenschaften 73, 679-680.

Landsman, R. E. (1991). Captivity affects behavioral physiology: Plasticity in signaling sexual identity. Experientia 47, 31-38.

Landsman, R. E. (1993). Sex differences in external morphology and electric organ discharges in imported Gnathonemus petersii (Mormyriformes). Anim. Behav. 46, 417-429.

Landsman, R. E., and Moller, P. (1988). Testosterone changes the electric organ discharge and external morphology of the mormyrid fish, Gnathonemus petersii (Mormyriformes). Experientia 44, 900-903.

Landsman, R. E., Jou, S. H., and Moller, P. (1987). Stress obscures signalling of sexual identity in Gnathonemus petersii (Mormyriformes). In "Reproductive Physiology of Fish" (D. R. Idler, L. W. Crim, and J. M. Walsh, eds.), p. 307. Memorial University of Newfoundland, St. John's.

Landsman, R. E., Harding, C. F., Moller, P., and Thomas, P. (1990). The effects of androgens and estrogen on the external morphology and electric organ discharge waveform of Gnathonemus petersii (Mormyridae, Teleostei). Horm. Behav. 24, 532-553.

Lissmann, H. W. (1951). Continuous electrical signals from the tail of a fish, Gymnarchus niloticus Cuv. Nature (London) 167, 201-202.

Lissmann, H. W. (1958). On the function and evolution of electric organs in fish. J. Exp. Biol. 35, 156-191.

Lissmann, H. W., and Machin, K. E. (1958). The mechanism of object location in Gymnarchus niloticus and similar fish. J. Exp. Biol. 35, 451-486.

Lücker, H., and Kramer, B. (1981). Development of a sex difference in the preferred 
latency response in the weakly electric fish, Pollimyrus isidori (Cuvier et Valenciennes) (Mormyridae, Teleostei). Behav. Ecol. Sociobiol. 9, 103-109.

Matsubara, J., and Heiligenberg, W. (1978). How well do electric fish electrolocate under jamming? J. Comp. Physiol., A 125, 285-290.

- Maynard Smith, J. (1991). Theories of sexual selection. Trends Ecol. Evol. 6, 146-151.

Mazeaud, M. M., and Mazeaud, F. (1981). Adrenergic responses to stress in fish. In "Stress and Fish" (A. D. Pickering, ed.), pp. 49-75. Academic Press, New York.

McGregor, P. K. (1991). The singer and the song: On the receiving end of bird song. Biol. Rev. 66, 57-81.

McGregor, P. K., and Westby, G. W. M. (1992). Discrimination of individually characteristic electric organ discharges by a weakly electric fish. Anim. Behav. 43, 977-986.

Mills, A., and Zakon, H. H. (1991). Chronic androgen treatment increases action potential duration in the electric organ of Sternopygus. J. Neurosci. 11, 2349-2361.

Moller, P. (1976). Electric signals and schooling behavior in a weakly electric fish, Marcusenius cyprinoides (Mormyriformes). Science 193, 697-699.

Moller, P. (1980a). Electroreception and the behaviour of mormyrid electric fish. Trends Neurosci. 3, 105-109.

Moller, P. (1980b). Electroperception. Oceanus 23, 42-54.

Moller, P., and Bauer, R. (1973). 'Communication' in weakly electric fish, Gnathonemus petersii (Mormyridae). II. Interaction of electric organ discharge activities of two fish. Anim. Behav. 21, 501-512.

Moller, P., and Brown, B. (1990). Meristic characters and electric organ discharge of Mormyrops curviceps Roman (Teleostei: Mormyridae) from the Moa River, Sierra Leone, West Africa. Copeia 1990(4), 1031-1040.

Moller, P., and Serrier, J. (1986). Species recognition in mormyrid weakly electric fish. Anim. Behav. 34, 333-339.

Moller, P., Serrier, J., Squire, A., and Boudinot, M. (1982). Social spacing in the mormyrid fish Gnathonemus petersii (Pisces): A multisensory approach. Anim. Behav. 30, 641-650.

Moller, P., Serrier, J., and Bowling, D. (1989). Electric organ discharge displays during social encounter in the weakly electric fish Brienomyrus niger L. (Mormyridae). Ethology 82, 177-191.

Myrberg, A. A., and Riggio, R. J. (1985). Acoustically mediated individual recognition by a coral reef fish (Pomacentrus partitus). Anim. Behav. 33, 411-416.

Neuweiler, G. (1984). Foraging, echolocation and audition in bats. Naturwissenschaften 71, 446-455.

Neuweiler, G. (1993). "Biologie der Fledermäuse." Thieme, Stuttgart.

Payne, R. (1962). How the barn owl locates prey by hearing. Living Bird 1, 151-159.

Rankin, J. C., and Jensen, F. B., eds. (1993). "Fish Ecophysiology." Chapman \& Hall, London.

Russell, C. J., Myers, J. P., and Bell, C. C. (1974). The echo response in Gnathonemus petersii (Mormyridae). J. Comp. Physiol. A 92, 181-200.

Scheich, H. (1977). Neural basis of communication in the high frequency electric fish, Eigenmannia virescens (jamming avoidance response). I. Open loop experiments and the time domain concept of signal analysis. J. Comp. Physiol., A 113, 181-206.

Scheich, H., Gottschalk, B., and Nickel, B. (1977). The jamming avoidance response in Rhamphichthys rostratus: An alternative principle of time domain analysis in electric fish. Exp. Brain Res. 28, 229-233.

Serrier, J., and Moller, P. (1981). Social behavior in mormyrid fish (Mormyriformes, Pisces): 
short and long-term changes associated with repeated interactions. In "Sensory Physiology of Aquatic Lower Vertebrates”' (T. Szabo and G. Czéh, eds.), Vol. 31, pp. 221-233. Pergamon Press/Akadémiai Kiadó, Budapest.

Shannon, C. E., and Weaver, W. (1949). "The Mathematical Theory of Communication." Univ. of Illinois Press, Urbana.

Shumway, C. A., and Zelick, R. D. (1988). Sex recognition and neuronal coding of electric organ discharge waveform in the pulse-type weakly electric fish, Hypopomus occidentalis. J. Comp. Physiol. A 163, 465-478.

Suga, N. (1990). Biosonar and neural computation in bats. Sci. Am. 262(6), 34-41.

Szabo, T. (1967). Activity of peripheral and central neurons involved in electroreception. In "Lateral Line Detectors" (P. Cahn, ed.), pp. 295-311. Indiana Univ. Press, Bloomington.

Szabo, T. (1974). Anatomy of the specialized lateral line organs of electroreception. In "Handbook of Sensory Physiology" (A. Fessard, ed.), Vol. III, Part 3, pp. 13-58. Springer-Verlag, Berlin and New York.

Szabo, T., and Fessard, A. (1974). Physiology of electroreceptors. In "Handbook of Sensory Physiology" (A. Fessard, ed.), Vol. III, Part 3, pp. 59-124. Springer-Verlag, Berlin and New York.

Teyssèdre, C., Boudinot, M., and Minisclou, C. (1987). Categorisation of interpulse intervals and stochastic analysis of discharge patterns in resting weak-electric fish (Gnathonemus petersii). Behaviour 102, 264-282.

Thornhill, W. B., and Levinson, S. R. (1987). Biosynthesis of electroplax sodium channels in Electrophorus electrocytes and Xenopus oocytes. Biochemistry 26, 4381-4388.

von der Emde, G. (1990). Discrimination of objects through electrolocation in the weakly electric fish, Gnathonemus petersii. J. Comp. Physiol. A 167, 413-421.

von der Emde, G., and Bleckmann, H. (1992). Extreme phase-sensitivity of afferents which innervate mormyromast electroreceptors. Naturwissenschaften 79, 131-133.

von Frisch, K. (1967). "The Dance Language and Orientation of Bees." Harvard Univ. Press (Belknap), Cambridge, MA.

Watanabe, A., and Takeda, K. (1963). The change of discharge frequency by a.c. stimulus in a weak electric fish. J. Exp. Biol. 40, 57-66.

Waxman, S. G., Pappas, G. D., and Bennett, M. V. L. (1972). Morphological correlates of functional differentiation of nodes of Ranvier along single fibers in the neurogenic electric organ of the knife fish, Sternarchus. J. Cell Biol. 53, 210-224.

Westby, G. W. M. (1975a). Comparative studies of the aggressive behaviour of two gymnotid electric fish (Gymnotus carapo and Hypopomus artedi). Anim. Behav. 23, 192-213.

Westby, G. W. M. (1975b). Has the latency dependent response of Gymnotus carapo to discharge-triggered stimuli a bearing on electric fish communication? J. Comp. Physiol. A 96, 307-341.

Westby, G. W. M. (1979). Electrical communication and jamming avoidance between resting Gymnotus carapo. Behav. Ecol. Sociobiol. 4, 381-393.

Westby, G. W. M., and Kirschbaum, F. (1982). Sex differences in the waveform of the pulse-type electric fish, Pollimyrus isidori (Mormyridae). J. Comp. Physiol., A 145, 399-403.

Wier, C. C., Jesteadt, W., and Green, D. (1977). Frequency discrimination as a function of frequency and sensation level. J. Acoust. Soc. Am. 61, 178-184.

Wilson, E. O. (1975). "Sociobiology: The New Synthesis." Harvard Univ. Press, Cambridge, MA.

Wu, C. H. (1984). Electric fish and the discovery of animal electricity. Am. Sci. 72, 598-607.

Zwicker, E. (1982). "Psychoakustik." Springer-Verlag, Berlin and New York. 